\title{
Exosomes as Mediators of the Systemic Adaptations to Endurance Exercise
}

\author{
Adeel Safdar ${ }^{1}$ and Mark A. Tarnopolsky ${ }^{1,2}$ \\ ${ }^{1}$ Department of Pediatrics, McMaster University, Hamilton, Ontario L8N 3Z5, Canada \\ ${ }^{2}$ Department of Pediatrics \& Medicine, McMaster University, Hamilton, Ontario L8N 3Z5, Canada \\ Correspondence: tarnopol@mcmaster.ca
}

Habitual endurance exercise training is associated with multisystemic metabolic adaptations that lower the risk of inactivity-associated disorders such as obesity and type 2 diabetes mellitus (T2DM). Identification of complex systemic signaling networks responsible for these benefits are of great interest because of their therapeutic potential in metabolic diseases; however, specific signals that modulate the multisystemic benefits of exercise in multiple tissues and organs are only recently being discovered. Accumulated evidence suggests that muscle and other tissues have an endocrine function and release peptides and nucleic acids into the circulation in response to acute endurance exercise to mediate the multisystemic adaptations. Factors released from skeletal muscle have been termed myokines and we propose that the total of all factors released in response to endurance exercise (including peptides, nucleic acids, and metabolites) be termed, "exerkines." We propose that many of the exerkines are released within extracellular vesicles called exosomes, which regulate peripheral organ cross talk. Exosomes (30-140 nm) and larger microvesicles [MVs] (100-1000 nm) are subcategories of extracellular vesicles that are released into the circulation. Exosomes contain peptides and several nucleic acids (microRNA [miRNA], messenger RNA [mRNA], mitochondrial DNA [mtDNA]) and are involved in intercellular/tissue exchange of their contents. An acute bout of endurance exercise increases circulating exosomes that are hypothesized to mediate organ cross talk to promote systemic adaptation to endurance exercise. Further support for the role of exosomes (and possibly $\mathrm{MVs}$ ) in mediating the systemic benefits of exercise comes from the fact that the majority of the previously reported myokines/exerkines are found in extracellular vesicles databases (Vesiclepedia and ExoCarta). We propose that exosomes isolated from athletes following exercise or exosomes bioengineered to incorporate one or many of known exerkines will be therapeutically useful in the treatment of obesity, T2DM, and other agingassociated metabolic disorders.

$\mathrm{H}$ abitual physical activity (exercise) is a fundamental component of human health. There is strong evidence that regular physical activity reduces the risk of chronic diseases and physical disability in later life (health span), and even extends life span (Chakravarty et al. 2008; Balbuena and Casson 2009; Brenner 2009; Bronas 2009; Buchner 2009; Di Francescomarino et al. 2009; Kruk 2009; Nader and Lundberg 2009; Parsons and King-Vanvlack

Editors: Juleen R. Zierath, Michael J. Joyner, and John A. Hawley

Additional Perspectives on The Biology of Exercise available at www.perspectivesinmedicine.org

Copyright (C) 2018 Cold Spring Harbor Laboratory Press; all rights reserved; doi: 10.1101/cshperspect.a029827

Cite this article as Cold Spring Harb Perspect Med 2018;8:a029827 
2009; Pedersen 2009a; Stuart et al. 2009; Bohm et al. 2010; Booth and Laye 2010; Herring et al. 2010; Kosmadakis et al. 2010; Warburton et al. 2010; Woodcock et al. 2011). In contrast, physical inactivity is a major threat to public health by increasing the risk of chronic metabolic diseases and their resultant impact on health-care budgets (Katzmarzyk et al. 2000; Katzmarzyk and Janssen 2004; Warburton et al. 2010). Importantly, physical activity is a modifiable risk factor for metabolic diseases (type 2 diabetes mellitus [T2DM] and obesity) and other chronic diseases, including cardiovascular disease, cancer, osteoporosis, osteoarthritis, and neuromuscular disorders (Balbuena and Casson 2009; Brenner 2009; Buchner 2009; Di Francescomarino et al. 2009; Kruk 2009; Nader and Lundberg 2009; Parsons and King-Vanvlack 2009; Stuart et al. 2009; ten Hacken 2009; Bohm et al. 2010; Booth and Laye 2010). The importance of developing effective countermeasures for the common metabolic diseases (T2DM and obesity) is evident in that an estimated 38 million lives are lost yearly from these disorders (T2DM and obesity) and nearly half of these occurred in those under 70 years of age (Mendis et al. 2015). Consequently, the World Health Organization has mandated that improving physical activity within the population is important to lower the incidence of common metabolic diseases (Mendis et al. 2015).

Most of the evidence for the benefits of exercise on the risk for metabolic disease has come from studies retrospectively evaluating the effects of habitual endurance exercise or prospective studies with an endurance exercise intervention. Retrospective epidemiological studies have shown that the incidence of T2DM is lower in those with higher levels of physical activity (Helmrich et al. 1991). This relationship is dose-dependent with the most active men and women showing a $35 \%-55 \%$ reduction in the incidence of T2DM and cardiovascular disease (American Association of Diabetes Education 2012). Prospective lifestyle interventions that include endurance exercise have been shown to improve glycemic control and insulin sensitivity in patients with both T2DM and dysglycemic obesity (Avery et al. 2012). A large prospective randomized controlled trial (Diabetes Prevention Program) found that a lifestyle intervention with modest nutritional modification and $150 \mathrm{~min} /$ wk moderate-intensity endurance exercise was more effective than the drug metformin at preventing T2DM development in those with dysglycemia over an $\sim 3$ year intervention period (Knowler et al 2002). Importantly, these lifestyle modification benefits were still evident 10 years after the original intervention (Diabetes Prevention Program Research Group et al. 2009). Similar intensive lifestyle interventions that include endurance exercise (Look AHEAD trial) have also been shown to improve quality of life (Zhang et al. 2016) and lower the risk of depression (Rubin et al. 2014) and kidney disease (Look AHEAD Research Group 2014). Somewhat surprisingly, the latter study did not show a positive effect on cardiovascular outcomes (Look AHEAD Research Group et al. 2013); however, that may be because of the high burden of cardiovascular disease at baseline and the fact that the patients already had T2DM and not just dysglycemia (Wing et al. 2013). Nevertheless, the economic benefits of the exercise-focused lifestyle intervention led to a health-care cost savings of $\$ 5280 /$ person $/ 10$ years (Espeland et al. 2014).

Collectively, the human epidemiology data presented above does show that long-term habitual endurance exercise is associated with a reduction in all-cause mortality and that the derived benefits are not just in tissues and organs that would be traditionally associated with exercise benefits (muscle, heart, metabolic disease-associated tissues), but also extend to other tissues/organs less often associated with exercise benefits such as brain, breast, and colon cancer risk, kidney, and even eye health (Zheng Selin et al. 2015). The multisystemic benefits of long-term endurance exercise were apparent in a prospective cohort study that followed health outcomes in runners and age-matched sedentary controls over a 21 -year period (Chakravarty et al. 2008). The latter study reported lower disability scores and all-cause mortality in the runners with fewer deaths because of cancer, infections, stroke, and coronary artery disease (Chakravarty et al. 2008). The benefits of run- 
ning on health appear to be long-lasting in that many of the benefits were apparent in the subgroup of runners who had run for as short as 1 month and stopped (Chakravarty et al. 2008). In addition to the epidemiological evidence for multisystemic benefits of running/endurance exercise, there is also teleological evidence that running was likely a factor in the departure of Homo sapiens from other primates (Bramble and Lieberman 2004).

It is currently not clear how exercise can confer such multisystemic benefits but it is likely that there are many overlapping mechanisms. For running/endurance exercise to allow for successful adaptation and evolutionary selection, it is likely that exerkines coevolved endocrine-like signaling pathways such that multiple tissues derived benefits from exercise and not just skeletal muscle per se. The concept of exercise and, in particular, muscle having an endocrine-like effect on distant tissues was first proposed by Bente Petersen and colleagues whereby the term "myokine" was used to denote such substances derived from skeletal muscle (Pedersen and Fischer 2007a; Pedersen and Febbraio 2012). The myokine concept has survived the test of time and there are currently many myokines that have since been discovered (Pedersen and Hojman 2012; Seldin et al. 2012; Lee et al. 2014; Rao et al. 2014; Crane et al. 2015; Covington et al. 2016; Neidert et al. 2016). Given the fact that there are clearly peptides that are released from nonmuscle tissue in response to acute exercise or exercise training (Hansen et al. 2015; Stanford et al. 2015), we have coined the term "exerkine" as a more general term referring to humoral factors (peptides, metabolites [Pedersen and Febbraio 2012], and RNA [microRNA, miRNA; messenger RNA, mRNA]) that are produced and secreted into circulation by any tissue/organ in response to exercise.

Given the evolutionary importance of both intercellular communication and physical activity to many aspects of human health, the objective of the current review is to describe how these processes are linked and why they are important in mediating the multisystemic benefits of endurance exercise. The main hypothesis put forward is that myokines/exerkines contained within extracellular vesicles (EVs) and in particular exosomes are important mediators of the intercellular communication process occurring in response to exercise in humans.

\section{MYOKINES/EXERKINES AS ENDOCRINE MEDIATORS OF THE SYSTEMIC EFFECTS OF EXERCISE}

The first published use of the term, "myokine" for a specific peptide appears from the seminal work of Bente Pedersen in which she proposed that, "... IL-6 and other cytokines, which are produced and released by skeletal muscles, exerting their effects in other organs of the body, should be named 'myokines"” (Pedersen et al. 2003). The term "myokine" also includes other molecules released by skeletal muscle in association with exercise, including miRNA, mRNA, long noncoding RNA (lncRNA), and even metabolites, which exert auto-, para-, or endocrine effects (Little et al. 2011a; Pedersen and Febbraio 2012). Interleukin (IL)- 6 was the first of the discovered myokines (Pedersen et al. 2004), and remains the most studied of the myokines (Pedersen et al. 2004; Pedersen and Fischer 2007a,b; Pedersen 2007, 2009b). Acute endurance exercise induces skeletal muscle IL-6 release that has an autocrine/paracrine effect to increase glucose uptake and free fatty acid oxidation in skeletal muscle (Pedersen 2007; Pedersen and Fischer 2007a,b). IL-6 functions also in an endocrine manner by stimulating adipocyte lipolysis and hepatic gluconeogenesis to enhance fuel availability for working muscle (Pedersen 2007; Pedersen and Fischer 2007a,b). Skeletal musclederived IL- 6 also signals to the gut and pancreatic $\alpha$ cells to release glucagon-like polypeptide that then signals to the pancreatic $\beta$ cells to induce insulin secretion (Wallenius et al. 2002).

Since the first discovery of IL-6 as a myokine, a number of other peptides have been discovered that are true myokines while others are produced and secreted by fat depots (adipokines), and regulate some adaptations to exercise (Pedersen 2009a,b, 2011; Pedersen and Febbraio 2012; Pedersen and Hojman 2012). Given the muscle, fat, liver (hepatokines), brain (neurokines), kidneys (nephrokines), and other 
organs (Pedersen 2009a,b, 2011; Pedersen and Febbraio 2012; Pedersen and Hojman 2012), it is likely that many will be linked to beneficial multisystemic cellular adaptations in the future. For example, myonectin, brain-derived neurotrophic factor (BDNF), and leukemia inhibitory factor (LIF) concentration increase in blood following acute exercise and modulate aspects of free fatty acid metabolism (Florholmen et al. 2006; Matthews et al. 2009; Seldin et al. 2012, 2013). Vascular endothelial growth factor A (VEGFA) is an exercise-induced myokine that functions in a paracrine manner to promote angiogenesis (Pedersen and Febbraio 2012). As predicted, BDNF is likely involved as a systemic myokine promoting neurogenesis in response to endurance exercise (Pedersen and Febbraio 2012). Cross talk between skeletal muscle and bone is likely mediated by the myokines insulin-like growth factor 1 (IGF-1) and fibroblast growth factor (FGF)-2 (Pedersen and Febbraio 2012; Lee et al. 2014).

The other class of molecule that has been best characterized as a myokine/exerkine are the miRNAs. miRNAs are short $(\sim 22$ nucleotides), nonpeptide-encoding RNA molecules that regulate posttranscriptional gene expression in many physiological processes, including embryonic stem cell development, oncogenesis, myogenesis, and substrate metabolism (Barreiro and Sznajder 2013; Fernandez-Hernando and Baldan 2013; Kuppusamy et al. 2013; Tani et al. 2013; Trounson 2013; Adlakha and Saini 2014; Chen and Verfaillie 2014). It has been estimated that miRNAs regulate up to one-third of the mammalian genome, further supporting a major role in regulating gene expression (Romao et al. 2014). The multiplier effect of miRNAs on biological processes comes from the fact that a single miRNA can target hundreds of mRNAs, and individual mRNAs can be targeted by many different miRNAs, thus providing a powerful, complex, and flexible regulatory potential (Romao et al. 2014). miRNAs are known to be involved in many aspects of the adaptive response to exercise, including mitochondrial biogenesis, myocardial remodeling, skeletal muscle angiogenesis and hypertrophy, contractile force generation, and substrate metabolism
(Safdar et al. 2009; Aoi et al. 2010; Nielsen et al. 2010, 2014a; Hoppeler et al. 2011; Timmons 2011; Russell et al. 2013; Mooren et al. 2014; Ooi et al. 2014).

Although initially thought to only act within the cell of production, it is now known that miRNAs are found in plasma and have been called circulating miRNAs (c-miRNAs) (Mooren et al. 2014; Hubal et al. 2016). c-miRNAs can be produced in one cell type and be transported in a paracrine- or endocrine-like fashion to effect distal tissues and influence tissue function (Valadi et al. 2007; Hubal et al. 2016; Muroya et al. 2016). The plasma concentration of c-miRNAs goes up rapidly during exercise as does their intracellular expression (Safdar et al. 2009; Russell et al. 2013; Mooren et al. 2014; Nielsen et al. 2014b). c-miRNAs have been reported to modulate various aspects of cellular metabolism that are regulated by exercise (Mohan et al. 2015; Margolis et al. 2016), and hence we propose c-miRNAs can act as exerkines and play a role in multisystemic adaptive benefits of exercise.

Several papers have reviewed the potential for myokines to mitigate aspects of aging-associated metabolic disorders and cancer (Pedersen and Fischer 2007b; Demontis et al. 2013; Di Raimondo et al. 2016). The next section will review the evidence for exercise to lower the risk of diabetes and obesity, aging-associated pathology, and cancer and review the main myokines/exerkines that mediate the effects.

\section{BIOLOGY AND EVOLUTION OF EXTRACELLULAR VESICLES}

Eukaryotic cells can communicate through direct juxtacrine signaling or by the release of soluble factors into the interstitial fluid or blood as endocrine signaling. In addition to the endocrine signaling to distant tissues, soluble factors can act on the cell of production (autocrine signaling) or with adjacent cells (paracrine signaling). Although endocrine signaling is classically mediated by peptides and steroid hormones (Thery et al. 2002), a wide variety of other factors can function as myokine factors, including mRNA, cytokines, chemokines, and 
miRNA. Peptides that are secreted into the extracellular space usually have a secretory signal sequence (one or more positively charged amino acids followed by a stretch of 6-12 hydrophobic residues) on the amino terminus that directs the growing polypeptide to the endoplasmic reticulum (ER) (Thery et al. 2002). In addition to this classical pathway, proteins that do not contain secretory sequences, pulsatile or stimulus-dependent peptides, and signaling molecules that may be labile within the extra- cellular environment, can be secreted in EVs called exosomes (Januszyk and Lima 2004; Hagiwara et al. 2014; Choi et al. 2015). EVs are traditionally characterized by size into (1) exosomes (20-140 nm), (2) microvesicles [MVs] (100-1000 nm), and (3) apoptotic bodies (500-5000 nm) (Fig. 1). A challenge to characterization by size alone is that the larger exosomes overlap with the smaller MVs. Consequently, biochemical characterization of the proteins and lipids in the vesicles can aid in their

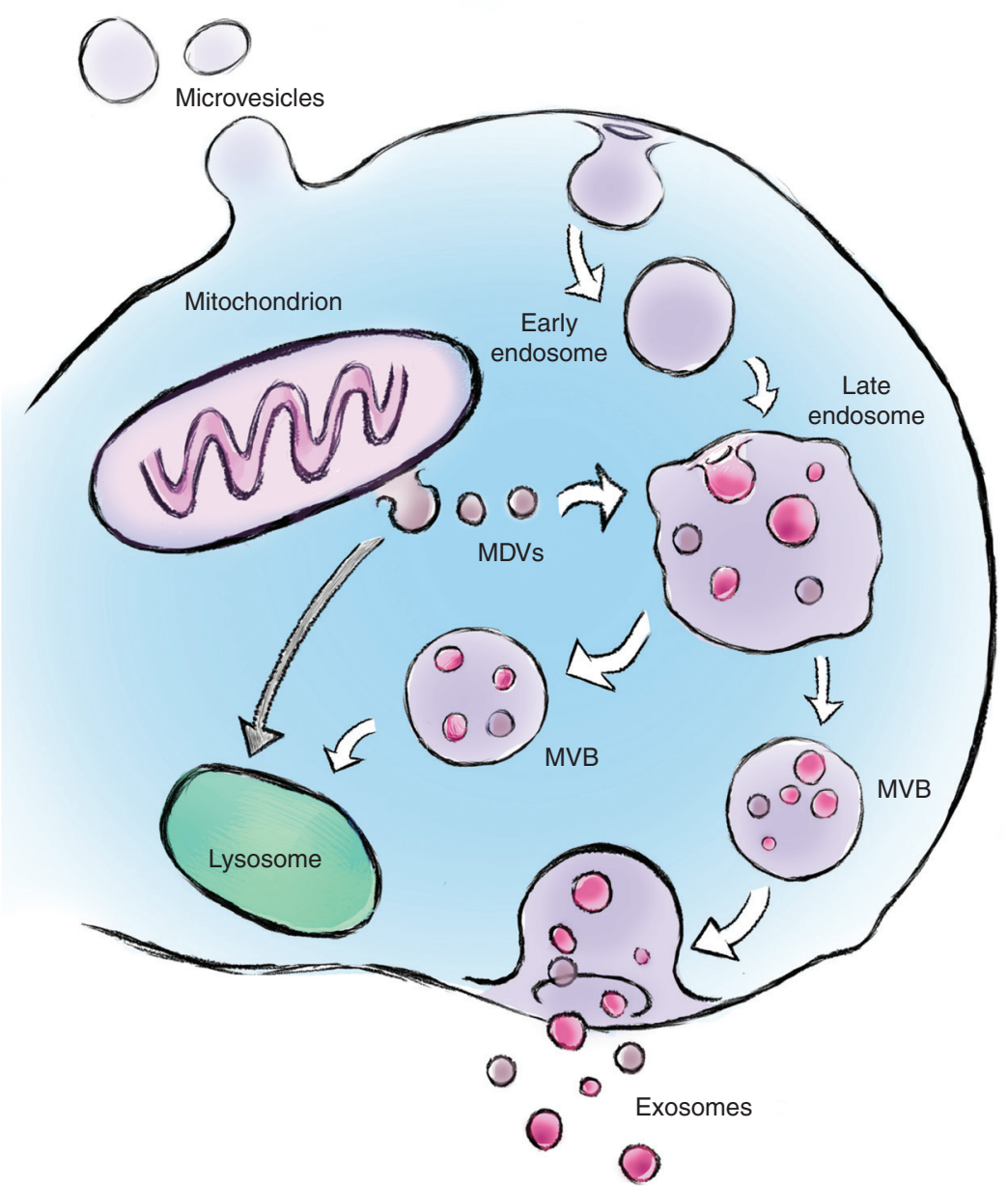

Figure 1. Biogenesis and secretion of extracellular vesicles. The maturation of early endosomes into late endosomes involves the formation of intraluminal vesicles derived from inward budding of the limiting membrane producing multivesicular bodies (MVBs). MVBs can translocate to the lysosome for degradation of vesicles and/or fuse with the plasma membrane to release exosomes (size 30-140 nm) into the extracellular milieu. Microvesicles (size 100-1000 nm) are formed by the outward budding of the plasma membrane. Mitochondria also release exosome-like vesicles called mitochondrial-derived vesicles (MDVs) $(70-150 \mathrm{~nm})$. MDVs can traffic to peroxisomes or to late endosomes/lysosomes. 
classification. Exosomes are enriched in specific proteins, including biogenesis markers (ALIX, TSG101), integrins and tetraspanins (CD9, CD63, CD81, CD82), heat shock proteins (HSP60, HSP70, HSP90), and transport and fusion proteins (ESCRT proteins, LAMP1/2, flotillin, Rab GTPases, annexins [I, II, III, IV]) (Mathivanan et al. 2010). Exosomes also contain an enrichment of various lipid species, including lysobisphosphatidic acid (LBPA), sphingolipids, cholesterol, ceramides, and glycerophospholipids (Mathivanan et al. 2010). In contrast, MVs are enriched in integrins, selectins (CD62, P-, and E-selectin), CD40 ligand, and $\mathrm{MHCI} / \mathrm{II}$, and the lipid component is higher in phosphatidlyserine and does contain cholesterol. Given that apoptotic bodies are fragments of cells, they do contain fragmented DNA, mitochondrial proteins, and ER markers. Further complicating the definition of exosomes versus $\mathrm{MVs}$ is the fact that vesicles containing classical exosomal markers and in the size range of exosomes $(50-100 \mathrm{~nm})$ have been shown to bud from the plasma membrane (Booth et al. 2006). Exosomes and MVs also contain a large number of proteins and other molecules such as RNA species (miRNA, mRNA, lncRNA), DNA, and mitochondrial DNA (mtDNA). The proteomic profile of exosomes and MVs can be found in public databases, including Vesiclepedia (www.microvesi cles.org), EVpedia (www.evpedia.info), and ExoCarta (www.exocarta.org). It is important to note that the challenges in separating the exosomes from the smaller MVs have led to some uncertainty as to the exact origin of the proteins found in such databases.

It is interesting that even down to prokaryotes there are methods of intercellular communication termed quorum sensing. Quorum sensing allows bacteria to coordinate their activities by sensing alterations in the environment and releasing proteins and lipids (including lipopolysaccharide [LPS]) that influence gene expression of adjacent bacteria (Deatherage and Cookson 2012). These intercellular communication molecules appear to be released within microbial membrane vesicles (MMVs) derived from the outer cell membrane. Gram-positive and Gram-negative bacteria release MMVs that range from 10 to $300 \mathrm{~nm}$ in diameter and contain LPS, peptides, lipoproteins, phospholipids, and toxins (McBroom et al. 2006; Lee et al. 2009; Kulp and Kuehn 2010; Rivera et al. 2010). The cell surface origin of the prokaryote MMVs is very similar to eukaryotic MVs as described below. Given that mitochondria have coevolved a symbiotic relationship with eukaryotic cells after their origins as purple photosynthetic bacteria (Gray 1989), it is not surprising that mitochondria retain a vesicle communication system named mitochondrial-derived vesicles (MDVs) (70-150 nm diameter) (Sugiura et al. 2014). MDVs that can shuttle to peroxisomes have been shown to transport cargo to peroxisomes (Andrade-Navarro et al. 2009; Soubannier et al. 2012) and MVBs/lysosomes (McLelland et al. 2014). The transport of MDVs from mitochondria to the lysosomes is activated by oxidative stress (Soubannier et al. 2012) before PINK/Parkin-dependent mitophagy (McLelland et al. 2014). It is speculative that the release of vesicles containing mtDNA from muscle and nerve for horizontal mtDNA transfer (Esquilin et al. 2012), could be derived from an MDV>endosome> exosome pathway. The latter would provide mechanistic support for the observed improvement in mtDNA mutational load in multiple tissues in the endurance-trained POLG1 mouse (Safdar et al. 2011a, 2015).

The initial concept of exosomes as mediators of biological processes in eukaryotic cells came from work on transferrin receptors and iron handing in reticulocytes published in 1983 by Clifford Harding and colleagues (Harding et al. 1983), and Rose Johnstone and colleagues (Pan and Johnstone 1983). Exosomes are secreted by many cell lines in culture and many cell types in vivo (Hwang 2013; Kalani et al. 2014; Record et al. 2014). Exosomes are primarily single membrane EVs, although rare double membrane exosomes are seen less commonly. Exosomes are formed by inward budding of the limiting membrane of late endosomes, leading to the formation of intraluminal vesicles within multivesicular bodies (MVBs) (Thery et al. 2002). MVBs can either fuse with lysosomes for 
proteolytic degradation, or they can fuse with the plasma membrane and release exosomes into extracellular fluid/blood (Fig. 1) (Thery et al. 2002). The fate of MVBs within a cell and the released MVs and exosomes are likely determined by their cargo (peptides, RNA, and DNA) and composition (surface proteins and lipid composition) (Raposo and Stoorvogel 2013).

The formation of lysosomal and secreted exosomes with the MVB is partially dependent on a series of evolutionarily conserved endosomal sorting complexes required for transport (ESCRT) proteins (ESCRT-0, I, II, and III) (Raposo and Stoorvogel 2013; Urbanelli et al. 2013; Yáñez-Mó et al. 2015). These proteins bind to the outer (cytosolic) membrane of the endosome (cytosolic face), and are involved in exosomal formation through interactions forming an ALIX/TSG-101/ESCRT-I complex, which activates ESCRT-II oligomerization and formation of an ESCRT-III complex (Raposo and Stoorvogel 2013; Urbanelli et al. 2013; YáñezMó et al. 2015). There are also ESCRT-independent MVB/exosome formation pathways (Stuffers et al. 2009; van Niel et al. 2011) that involve ceramide (Trajkovic et al. 2008). Sphingomyelinase is also involved in exosomal formation by liberating ceramide that helps with membrane invagination (Bianco et al. 2009). The fusion and release of exosomes to the extracellular fluid environment involves the soluble NSF attachment protein receptor (SNARE) pathway analogous to the pathways involved in neurotransmitter release and glucose transporter type 4 (GLUT-4) migration to the sarcolemma in response to exercise or insulin (Raposo and Stoorvogel 2013; Urbanelli et al. 2013; Yáñez-Mó et al. 2015). The membrane fusion between the MVBs and the plasma membrane is mediated by GTPases (Rab11, Rab27) that facilitate vesicular SNARE (on MVBs)/target SNARE (on plasma membrane) interaction (Raposo and Stoorvogel 2013; Urbanelli et al. 2013). The mechanism(s) triggering exosome release in response to acute exercise or exercise training in skeletal muscle and other tissues is not currently known; however, some of the classical pathways activated by acute exercise are likely important. A variety of stimuli including glutamate and $\mathrm{K}^{+}$activation of neurons, intracellular $\mathrm{Ca}^{2+}$ changes, ATP-mediated dendritic cell activation, and phosphatidic acid have all been shown to influence exosomal secretion/release (Skokos et al. 2003; Savina et al. 2005; Lachenal et al. 2011; Urbanelli et al. 2013). The $\mathrm{Ca}^{2+}$-mediated exosomal release is of particular interest in skeletal muscle given that the major $\mathrm{Ca}^{2+}$ transients that occur in the cytosol with contraction are known to signal many important processes through calcineurin, calcium/calmodulin-dependent protein kinases (CaMKs), and p38MAP kinase (Hood 2001).

Once released, exosomes interact with and modulate the metabolic behavior of the target cells in a variety of ways, which is hypothesized to be dependent on the cell type and material cargoed within the exosomes. Exosomes can (1) activate downstream signaling in the target cell via interaction of exosomal surface protein with receptors on the plasma membrane of the target cell; (2) fuse with the plasma membrane of the target cells, thus delivering their cargo into the cytosol of the target cell; and (3) be phagocytosed or endocytosed by the target cells, which can then be delivered to a specific organelle in the target cells (Mulcahy et al. 2014). The exact mechanism(s) by which exosomes are targeted to specific tissues is unclear; however, recent evidence in tumor cells show that specific integrins on the exosome surface are important in tissuehoming specificity (Hoshino et al. 2015).

Exosome biology is an emerging discipline in the past decade with most research focusing on the role of exosomes in various pathologies and in disease biomarker discovery (Wolfers et al. 2001; André et al. 2002; Thery et al. 2002; Aucher et al. 2013; Pope and Lässer 2013; Ramakrishnaiah et al. 2013). In contrast, the potential role for exosomes in exercise physiology/medicine is embryonic in development with only 17 references appearing in a PubMed (www.ncbi.nlm.nih.gov/pubmed) search on August 19, 2016. Conceptually, however, the role of exsosomes as mediators of the multisystemic benefits of exercise is attractive given that exosomes are known to function in an intercellular communication "signalosome" manner (Thery et al. 2002). Exosomes influence self(autocrine), adjacent (paracrine), or distant 
(endocrine) cells through juxtacrine signaling, direct activation of cell-surface receptors with exosome protein \pm lipid ligand interactions (receptor-mediated endocytosis), or by fusing the recipient cell plasma membrane (Thery et al. 2002). Exosomes are ubiquitously expressed and have been isolated from cell culture media, plasma, serum, saliva, amniotic fluid, breast milk, urine, ascites, and cerebrospinal fluid (Mathivanan and Simpson 2009; Urbanelli et al. 2013; Yáñez-Mó et al. 2015). There is currently no consensus on the "gold standard" for the isolation of exosomes or MVs; however, the most common methods use ultracentrifugation with and without a density gradient, polyethylene glycol, ultrafiltration, alone or a combination thereof (Baranyai et al. 2015; Wiklander et al. 2015; Rider et al. 2016; Weng et al. 2016). Irrespective of the isolation method used, it is important for future studies to carefully characterize the EVs from any source and we recommend that the reader consider and follow the guidelines set forth by the International Society for Extracellular Vesicles regarding the minimal requirements for EV categorization (Lötvall et al. 2014).

\section{PROMETABOLIC EXERKINES MITIGATE OBESITY AND TYPE 2 DIABETES}

Studies in the last four decades have determined that development of obesity and T2DM are mechanistically linked with skeletal muscle mitochondrial dysfunction (Simoneau et al. 1995; Morino et al. 2005, 2006; Ritov et al. 2010). Mitochondrial dysfunction (including attenuated mitochondrial biogenesis, reduced mitochondrial content, and/or lower oxidative capacity) in skeletal muscle contributes to various aspects of metabolic syndrome, likely because of the pathological accumulation of intracellular lipids and lipid intermediates that inhibit insulin signaling (Lowell and Shulman 2005; Morino et al. 2006; Petersen and Shulman 2006). Endurance exercise is touted as the gold-standard therapy for obesity and T2DM, and one of the mechanisms by which exercise circumvents insulin resistance in obesity and T2DM is by increasing skeletal muscle mitochondrial biogenesis and an overall improvement in mitochondrial bioenergetic capacity (Hawley 2004; Morino et al. 2006; Joseph and Hood 2014). Additionally, endurance exercise training promotes insulin signaling that results in both a greater abundance in GLUT4 and modulation of intracellular localization of GLUT4 to efficiently clear excess glucose from circulation, which may positively affect whole-body glycemic control (Dela et al. 1994; Ren et al. 1994; Gulve and Spina 1995; Phillips et al. 1996; Greiwe et al. 2000). Recently, endurance exercise has been shown to ameliorate adiposity and insulin resistance via promoting skeletal muscle-immune system-adipose tissue cross talk that leads to an induction of a thermogenic gene network resulting in browning of white adipose tissue (WAT) (Langin 2010; Boström et al. 2012; Lo and Sun 2013). Browning of WAT in response to endurance training, characterized by the upregulation of the uncoupling protein 1 (UCP1) content in subcutaneous WAT (scWAT), renders WAT to be metabolically active in dissipating excess energy as heat and is intimately linked with improved metabolic status in high-fat-fed diet murine model of obesity and T2DM and is thus an attractive therapeutic target (Kajimura et al. 2015).

The collection of exerkines, including irisin, meteorin-like (METRNL), and FGF-21, have emerged as important regulators of adipose tissue browning released systemically by skeletal muscle (irisin and METRNL), adipose tissue (METRNL), liver (FGF-21), and cells of the immune system (METRNL) (Boström et al. 2012; Fisher et al. 2012; Lee et al. 2014; Rao et al. 2014). The discovery of these exerkines has garnered much support for that notion that exerkines promote organ cross talk and mediate the endocrine effects on peripheral tissues to mitigate various aspects of metabolic syndrome, including fatty liver, dysglycemia, insulin resistance, increased adiposity, and exercise intolerance (Boström et al. 2012; Fisher et al. 2012; Lee et al. 2014; Rao et al. 2014). Endurance exercise is also known to potentially affect pancreatic physiology, including increase in pancreatic $\beta$ cell proliferation through insulin/IGF-1-mediated signaling (Choi et al. 2006). Studies have 
shown that circulatory levels of secreted peptide IGF-1 increase after both an acute bout of endurance exercise and exercise training in patients with T2DM and are directly related to an overall improvement in exercise-mediated metabolic homeostasis (Gregory et al. 2013; Mohajeri Tehrani et al. 2015). The hunt for exerkines like irisin, METRNL, FGF-21, IGF-1, and other humoral factors is concluded as instrumental in designing improved therapies for obesity, T2DM, and other aging-associated metabolic diseases and immediately necessitates future studies to unravel the identity of such exerkines.

In addition to peptides, altered levels of miRNA species both in tissues and circulation have been shown to play an important role in mediating metabolic diseases including obesity and T2DM (Sethupathy 2016). Impaired insulin signaling and dysglycemia in T2DM is linked with an impairment in the expression of the muscle-specific miRNAs (myo-miRs), miR-1 and miR133a (Granjon et al. 2009). miRNAs (miR-192, miR-193b) are reported to be higher in the plasma of prediabetic mice and humans (Párrizas et al. 2015.). miRNAs have also been implicated in the control of pancreatic $\beta$-cell function and fate (Filios and Shalev 2015). Incidentally, acute endurance exercise increases miR-1 and miR-133a in skeletal muscle, and miR-132 and miR-338-3p in the pancreas (Nielsen et al. 2010, 2014b; Radom-Aizik et al. 2012; Russell et al. 2013). Additionally, endurance exercise training normalized expression of miR-192 and miR-193b in prediabetic mice and humans (Párrizas et al. 2015). We and others have shown that an acute bout of endurance exercise influences the expression of miRNA species that are involved in regulating various aspects of skeletal muscle metabolism, including regulating peroxisome proliferator-activated receptor $\gamma$ coactivator $1 \alpha$ and $\beta$ (PGC- $1 \alpha$ ) $\beta$ ) expression, a transcription coactivator and master regulator of muscle mitochondrial biogenesis in response to endurance exercise (Pilegaard et al. 2003; Safdar et al. 2009, 2011b; McLean et al. 2015). PGC- $1 \alpha$ and its responsive downstream mitochondrial genes network are significantly down-regulated in skeletal muscle of patients with T2DM (Mootha et al. 2003). Interestingly, muscle-specific overexpression of PGC- $1 \alpha$ is associated with increased mitochondrial biogenesis, improvements in insulin sensitivity and glucose homeostasis, and browning of WAT (Puigserver et al. 1998; Lin et al. 2003), as well as improvements in vascular function in T2DM (Sawada et al. 2014). Together, the above data suggests that obesity and T2DM alter the expression of several species of muscle miRNA and c-miRNA. Since endurance exercise normalizes the altered expression of these miRNA species in some metabolic disorders, we propose that these miRNA species may act as prometabolic exerkines. Certainly, there is a crucial need for mechanistic (loss- and gain-of-function) studies to evaluate the role of exercise-responsive miRNA species in affecting overall cellular metabolism.

Chronic low-grade systemic inflammation is another of the hallmarks of obesity and T2DM (Sell and Eckel 2009; Gregor and Hotamisligil 2011; Cipolletta et al. 2012). Both in vitro and in vivo studies have shown that visceral adipocytes promote systemic inflammation by secreting various cytokines such as IL- 6 , tumor necrosis factor (TNF)- $\alpha$, and transforming growth factor (TGF)- $\beta 1$ that may have proximal and distal proinflammatory and metabolic remodeling effects associated with development of secondary pathologies including nonalcoholic fatty liver diseases, cancer, etc. Recently, adipocytes have been shown to also secrete exosomes (Ferrante et al. 2015; Hubal et al. 2016), and adipocyte-derived exosomes mediate activation of macrophages that secrete TNF- $\alpha$ and IL-6, and promote insulin resistance in highfat-diet-induced murine model of obesity (Deng et al. 2009). Exosomes derived from visceral adipose tissue promoted hepatic inflammatory and fibrotic signaling pathways that may contribute to nonalcoholic fatty liver disease (Koeck et al. 2014). Since exercise is regarded as a gold-standard therapy to mitigate molecular pathologies associated with obesity and T2DM, we propose that the humoral factors that are touted to have antiobesogenic properties (Boström et al. 2012; Fisher et al. 2012; Lee et al. 2014; Rao et al. 2014) are released systemi- 
A. Safdar and M.A. Tarnopolsky

cally as part of exosomes to induce browning in peripheral adipose tissue depots.

\section{ANTI-TUMOROGENIC EXERKINES}

A number of studies have found that exercise is associated with a lower risk of several types of cancer, including breast, esophagus, ovarian, and colon (Chakravarty et al. 2008; Lee et al. 2013; Friedenreich et al. 2016; Gong et al. 2016; Moore et al. 2016). A recent meta-analysis of 1.44 million people found that higher levels of leisure time physical activity were associated with a lower risk of 13 of 26 different types of cancer (Moore et al. 2016). The two cancers whose risk was shown to be increased with higher levels of leisure time activity was melanoma (1.27 relative risk) and prostate (1.05 relative risk) cancer (Moore et al. 2016). The latter observation regarding melanoma risk is likely because of the higher sun exposure in those doing activity outside and illustrates the importance of sun protection in those who do their physical activity outdoors. There was a small increased risk of prostate cancer also in the large study (Moore et al. 2016), and tiny increased risk occurred in another study of cross-country skiers (Hållmarker et al. 2015). The latter study also found a lower risk of cancer across all types, especially in those with lower finishing times in races, presumably reflective of a higher physical fitness level and more hours of training (Hållmarker et al. 2015). In addition to cancer risk, there is also evidence that exercise is associated with health improvements after diagnosis (Fong et al. 2012; Friedenreich et al. 2016), even for prostate cancer (Bourke et al. 2016). In contrast to the benefits of physical fitness, adipose-derived exosomes are shown to promote melanoma progression in both mice and humans (Lazar et al. 2016).

One candidate myokine/exerkine mediating the benefits of exercise on cancer risk and progression is IL-6 (Pedersen et al. 2016). This study found that acute exercise was associated with an epinephrine and muscle-derived IL-6mediated redistribution of natural killer cells to the tumor (Pedersen et al. 2016). The study also reported $\sim 60 \%$ reduction in tumors across five different models (Pedersen et al. 2016). IL-6, however, is complex in that cancer patients have a chronic elevation of IL- 6 that can contribute to cancer cachexia (Mathur and Pedersen 2008; Hetzler et al. 2015). This apparent paradox is explained by the pulsatility of IL-6 that is induced by bouts of exercise that lead to an activation of muscle satellite cells and contribute to muscle hypertrophy and/or maintenance (Toth et al. 2011; Belizario et al. 2016; Joanisse and Parise 2016). Another myokine that could mediate the beneficial effects of exercise on colon cancer is secreted protein acidic and rich in cysteine (SPARC) (Aoi et al. 2013). This study found that acute endurance exercise led to the up-regulation of skeletal muscle SPARC and plasma SPARC protein and that the benefits of exercise on chemically induced colon cancer was not evident in the SPARC-null mice (Aoi et al. 2013). Furthermore, spent media from stretched myoblasts inhibited the proliferation of colon cancer cells in vitro (Aoi et al. 2013).

\section{AGING AND THE MULTISYSTEMIC BENEFITS OF ENDURANCE EXERCISE}

Habitual physical activity/endurance exercise and higher levels of physical fitness have been consistently shown to reduce all causes of mortality (Chakravarty et al. 2008; Woodcock et al. 2011; Bouchard et al. 2015; Schnohr et al. 2015; Lin et al. 2016). The age-associated decline of function of many organs and tissues has also been shown to be attenuated in those who regularly perform exercise or are more physically fit (Chakravarty et al. 2008; Balbuena and Casson 2009; Brenner 2009; Bronas 2009; Buchner 2009; Di Francescomarino et al. 2009; Kruk 2009; Nader and Lundberg 2009; Parsons and King-Vanvlack 2009; Pedersen 2009a; Stuart et al. 2009; Bohm et al. 2010; Booth and Laye 2010; Herring et al. 2010; Kosmadakis et al. 2010; Warburton et al. 2010; Woodcock et al. 2011). Aging is a complex phenomenon that clearly has many fundamental causes that may differ among individuals. It has been suggested that there are nine hallmarks of aging, including genomic instability, telomere shortening, epige- 
netic alterations, altered proteostasis, deregulated nutrient sensing, mitochondrial dysfunction, cellular senescence, stem-cell exhaustion, and altered intercellular communication (Lopez-Otin et al. 2013). Several of these processes and other important components of aging can be linked to mitochondrial dysfunction, including telomere shortening, oxidative stress, inflammation, and even genomic instability (Safdar et al. 2011a, 2015; Kolesar et al. 2014). Training studies in murine models of aging further support the epidemiological data in showing that exercise training attenuates the ageassociated deleterious effects on mitochondria, antioxidant enzyme activity, and oxidative damage in skeletal muscle, adipose tissue, kidney, brain, and liver (Boveris and Navarro 2008; Sutherland et al. 2009; Safdar et al. 2011a; Clark-Matott et al. 2015).

It has previously been shown that the benefits of endurance exercise are multisystemic in nature and that these benefits are associated with improvements in cellular functional, structural, and health outcome metrics (van Praag et al. 1999; Boveris and Navarro 2008; Chakravarty et al. 2008; Safdar et al. 2011a; Cameron et al. 2012; Devries et al. 2013; Dutheil et al. 2013; Samjoo et al. 2013; Moon et al. 2016). Although the phenotypic benefits of habitual physical activity on multiple tissues and organs are well established in rodents (van Praag et al. 1999; Boveris and Navarro 2008) and humans (Chakravarty et al. 2008), the complex array of interorgan and intertissue signaling that mediates and coordinates this phenomenon remains largely unknown (Moon et al. 2016). To develop effective countermeasures for inactivity-associated disorders, such as obesity and T2DM, it is important to understand the biology of activity-induced interorgan communication (Kruk 2009; Stuart et al. 2009; Warburton et al. 2010).

One approach that we have used recently is to study the multisystemic effects of chronic endurance exercise training in a murine model of aging/mitochondrial dysfunction called the POLG1 mutator mouse. Endurance exercise training in this model over most of their life span was associated with a reduction in mitochondrial dysfunction, a dramatic preservation of tissue histology and a prolonged life span (Safdar et al. 2011a). We have also shown that Master's athletes have more youthful skin histology and preserved mitochondrial capacity versus sedentary people (Crane et al. 2015). The combination of both epidemiological studies showing the protective effects of exercise in multiple nonexercised tissues (skin, kidney, brain, eyes) and the dramatic benefits seen in the progeroid POLG1 murine aging/mitochondrial dysfunction model (Safdar et al. 2011a) provide strong support for the concept of myokines/exerkines functioning in an endocrinelike manner to coordinate the multisystemic beneficial response to habitual physical activity (Little et al. 2011a; Safdar et al. 2011a; Pedersen and Febbraio 2012).

\section{ARE EXOSOMES IMPORTANT MEDIATORS OF THE MULTISYSTEMIC BENEFITS OF EXERCISE?}

There has been very little attention given to the mechanism(s) of myokine/exerkine release into circulation. It is known that the quintessential myokine, IL-6, is rapidly depleted from muscle during contractions and that the IL- 6 was within vesicle structures (Lauritzen et al. 2013), indirectly implying that IL-6 may indeed be released as part of the exosome pathway. Furthermore, HSP70 and HSP72 are reported to be released in exosomes from macrophages in response to acute heat stress (Lancaster and Febbraio 2005a,b). An increase in HSP72 abundance in skeletal muscle mitigates the dysglycemic effects of high-fat feeding in mice and increases mitochondrial abundance and exercise capacity (Henstridge et al. 2014).

Although the above evidence supporting that myokines/exerkines are released in exosomes is circumstantial and rather incomplete, there are several lines of evidence suggesting that exosomes do play a role in mediating the multisystemic effects of endurance exercise. First, the role of exosomes/MVs as mediators of intercellular communication is a highly conserved process throughout evolution and across prokaryotes, plants, and eukaryotes, including yeast and fungi. As described above, exosomes 
and possibly MVs can transfer a wide variety of biomolecules (peptides, mRNA, DNA, miRNA, mtDNA, etc.) between cells using receptor-dependent and -independent mechanisms (Lötvall et al. 2014). Strong evidence suggests that skeletal muscle functions as a secretory organ (Pedersen and Febbraio 2012), even in vitro (Forterre et al. 2014). It has also been shown that skeletal muscle releases exosomes that contain hundreds of peptides (Aswad et al. 2014), and myoblast differentiation into myotubes resulted in a change in the secretory pattern involving 437 proteins (Ojima et al. 2014). In the latter study, only $10 \%$ of the peptides had a canonical secretory sequence with $43 \%$ being nonclassical secreted proteins lacking an amino-terminus secretory sequence and $65.3 \%$ of the peptides being bioinformatically linked to exosomes (www.exocarta.org) (Ojima et al. 2014). Although still a preliminary observation, our pilot data showing that the exosome marker, apoptosis-linked gene 2 interacting protein X (ALIX) was present in skeletal muscle and was severely depleted immediately after acute endurance exercise, supports that exosomes are present in skeletal muscle and released in response to endurance exercise (Safdar et al. 2016).

Collectively, the above data suggests that skeletal muscle releases many peptides in response to cellular stress or physiological processes but the link between acute endurance exercise and exosome release and their role in mediating multisystemic benefits is still very limited. To date, there has been only one study reporting the effects of acute exercise on serum EVabundance in humans (Fruhbeis et al. 2015). The response of EVs was evaluated in response to acute endurance exercise (both cycling and treadmill running) using ultracentrifugation and filtration to quantify small EVs/exosomes and MVs. The found an acute intensity-dependent increase in small EVs/exosomes but not $\mathrm{MVs}$ in response to both modes of exercise with a return to resting levels $90 \mathrm{~min}$ after cycling and $180 \mathrm{~min}$ after running (Fruhbeis et al. 2015). It is unclear what proportion of the small $\mathrm{EV} /$ exosome fraction was in fact exosomes for the approximate mean vesicle diameter was $>140 \mathrm{~nm}$ in the representative images from the treadmill data (Fruhbeis et al. 2015), and because this is the upper limit of the size of exosomes (Harding et al. 2013), it is likely that a substantial number of these vesicles were small MVs. The acute exercise study also found that HSP70 content of EV s was slightly elevated postexercise (Fruhbeis et al. 2015). The same group has also reported that the acute endurance exercise induced increase in cell-free DNA (cfDNA) occurred independent of MVs (Helmig et al. 2015). Although not skeletal muscle derived, one study reported that an acute bout of endurance exercise was associated with a proangiogenic gene expression profile in CD62E + ve and CD34+ve blood cells (Lansford et al. 2016). In the latter study, men showed acute exercise-induced increase in CD62E + ve cell microparticles and women showed higher CD34+ ve cell microparticle abundance (Lansford et al. 2016). A study using the $\mathrm{db} / \mathrm{db}$ murine model of T2DM found that cardiac-derived exosomes containing several miRNAs (miR-455, miR29b, miR-323-5p, and miR-466) were released in response to acute endurance (Chaturvedi et al. 2015). They speculated that the increase in these specific miRNAs would negatively influence matrix metalloprotease 9 (MMP9) gene expression and lessen cardiac fibrosis (a known pathology with aging and T2DM) (Chaturvedi et al. 2015). To date, there have been no studies looking at $\mathrm{MV} / \mathrm{EV}$ release in response to other modes of exercise; however, the increase in plasma CD34+ve cells following an acute bout of sprint interval exercise (Harris et al. 2014), combined with the above data indirectly implies that other modes of exercise may lead to the release of exosomes and/or MVs into circulation.

The limited collective data regarding exercise and exosome/MV release and function is very scant but is likely to be expanded upon over the next several years (Safdar et al. 2016). We have previously reported that up to $75 \%$ of the reported exerkines/myokines were listed in the annotation of peptides that have been reported to exist in exosomes/MVs (ExoCarta and Vesiclepedia) (Safdar et al. 2016). We have updated this list by including more of the reported myokines/exerkines using a PubMed (www.pubmed.org) search on November 3, 
2016 and the latest annotation of the exosome and/or MV listings on the www.exocarta.org and www.microvesicles.org websites. We found that of the 35 myokines/exerkines, 51\% were listed in www.exocarta.org and 80\% in www .microvesicles.org (Table 1).

Collectively, the above data strongly suggests that many of the reported myokines/exerkines are contained within exosomes and possibly MVs. Furthermore, we propose that the myokines and exerkines cargoed within exosomes are integral in promoting interorgan cross talk that modulate the systemic benefits of endurance exercise (Fig. 2).

\section{FUTURE DIRECTIONS}

The first challenge moving forward will be the ability to separate exosomes from MVs and agree on a definition of size. Exosomes are generally assumed to be between 30 and $140 \mathrm{~nm}$; however, this has been based primarily on nanoparticle counting and dynamic light scattering methods that tend to overestimate the size. For example, when measuring the same exosomal fraction with three different methods, investigators reported a size of 30-50 nm using scanning electron microscopy, $110-120 \mathrm{~nm}$ using nanoparticle counting, and 210-220 nm using dynamic light scattering methods (Sokolova et al. 2011). Our data agrees with this for we find that exosome size is about $30 \%-50 \%$ smaller using the gold standard of cryoelectron microscopy as compared with dynamic light scattering (unpubl.). Another issue is that particles that bud off the plasma membrane (MVs) have been reported in the size range that overlaps with exosomes $(20-120 \mathrm{~nm})$ (Booth et al. 2006). As we also discussed above, several studies that claim to have highly purified exosomal fractions show nanoparticle tracking data with much of the area under the curve above the $140 \mathrm{~nm}$ size (El-Andaloussi et al. 2012). In addition, there appears to be some overlap in the peptides that are reported to be vesicle exclusive (Soekmadji et al. 2013). We would recommend that it is important to follow consensus statements regarding experimental rigor such as that released by the International
Society for Extracellular Vesicles in 2014 (Lötvall et al. 2014).

Another issue that will require in depth analysis will be exercise-specific questions such as the duration, intensity, and mode of exercise and the relationship to exosomes and MVs. It is known that many of the classical adaptations to endurance exercise also occur in response high intensity interval training (Little et al. 2011b,c; Earnest et al. 2013), and evaluating the exosome and MV characteristics will be revealing. Along these lines, resistance exercise has clearly been shown to be an effective countermeasure for sarcopenia (Tarnopolsky et al. 2007), and characterizing the myokines/exerkines in this mode of exercise will be important. It is also known that unaccustomed lengthening contractions (sometime called eccentric) can damage contractile elements (Stupka et al. 2001), and determining whether this mode of exercise impairs exosome release and/or alters the ratios of exosome/MV release will be low-hanging fruit. There is an impending need to study the effects of aging and chronic metabolic disease on exosome biology and circulating exosomal biomarkers. Exercise is generally regarded as the gold-standard therapy to promote both health span and life span, and we propose that one of the ways that endurance exercise mitigates chronic metabolic diseases is by promoting homeostatic cross talk between organs and tissues. It will also be very important to determine how chronic exercise training affects the basal and acute exercise response of exosomes and MVs. These studies should use a repeated measures design and also covariate age, sex, and comorbidities (i.e., obesity and T2DM). Our preliminary data comparing the serum exosome dynamic light scattering profile between a middle-aged sedentary male and a very well trained endurance athlete showed very distinctive profiles, and proteomics, transcriptomics, and metabolomics characterization of such vesicles should provide important information.

\section{CONCLUSIONS}

The multisystemic benefits of habitual endurance exercise on multiple organs and tissues and 
A. Safdar and M.A. Tarnopolsky

Table 1. Presence of known exercise-responsive myokines/adipokines (exerkines) within extracellular vesicle compendiums

\begin{tabular}{|c|c|c|c|}
\hline Protein & $\begin{array}{c}\text { www } \\
\text {.exocarta.org }\end{array}$ & $\begin{array}{c}\text { www } \\
\text {.microvesicles.org }\end{array}$ & Association \\
\hline Adiponectin (AdipoQ) & $\mathrm{Y}$ & $\mathrm{Y}$ & Obesity, T2DM \\
\hline Apelin (APLN) & $\mathrm{Y}$ & $\mathrm{Y}$ & Obesity, cancer \\
\hline $\begin{array}{l}\text { Brain-derived neurotrophic factor } \\
\text { (BDNF) }\end{array}$ & $\mathrm{Y}$ & $\mathrm{Y}$ & Obesity, cancer \\
\hline Betatrophin (ANGPTL8) & $\mathrm{N}$ & $\mathrm{N}$ & $\mathrm{T} 2 \mathrm{DM}$ \\
\hline Cathepsin B (CTSB) & $\mathrm{Y}$ & $\mathrm{Y}$ & T2DM, cognition, cancer \\
\hline $\begin{array}{l}\text { Cbp/p300-interacting transactivator } \\
\text { (CITED4) }\end{array}$ & $\mathrm{N}$ & $\mathrm{Y}$ & Cancer, muscle hypertrophy \\
\hline Chemokine ligand 1 (CXCL1) & $\mathrm{Y}$ & $\mathrm{Y}$ & Lung fibrosis, asthma \\
\hline Chemokine ligand 2 (CCL2) & $\mathrm{Y}$ & $\mathrm{Y}$ & Systemic inflammation, cancer \\
\hline Chitinase 3-like 1 (CHI3L1) & $\mathrm{N}$ & $\mathrm{Y}$ & Obesity, myocyte proliferation \\
\hline Colony-stimulating factor 3 (CSF3) & $\mathrm{Y}$ & $\mathrm{Y}$ & Unknown \\
\hline $\begin{array}{l}\text { Connective tissue growth factor } \\
\text { (CTGF) }\end{array}$ & $\mathrm{Y}$ & $\mathrm{Y}$ & Connective tissue, ? muscle growth \\
\hline Dipeptidyl-peptidase 4 (DPP4) & $\mathrm{Y}$ & $\mathrm{Y}$ & T2DM, ? intestinal function \\
\hline Fibroblast growth factor (FGF)-2 & $\mathrm{N}$ & $\mathrm{Y}$ & $\begin{array}{l}\text { Chondrocyte and muscle } \\
\text { regeneration }\end{array}$ \\
\hline FGF-21 & $\mathrm{N}$ & $\mathrm{N}$ & Obesity, T2DM, NAFLD \\
\hline Follistatin-like 1 (FSTL-1) & $\mathrm{Y}$ & $\mathrm{Y}$ & Endothelial function \\
\hline $\begin{array}{l}\text { Growth differentiation factor } 11 \\
\text { (GDF-11) }\end{array}$ & $\mathrm{Y}$ & $\mathrm{Y}$ & ? Muscle growth \\
\hline $\begin{array}{l}\text { Growth differentiation factor } 15 \\
\text { (GDF-15) }\end{array}$ & $\mathrm{N}$ & $\mathrm{Y}$ & $\begin{array}{l}\text { Skeletal and cardiac muscle, ? } \\
\text { neurogenesis }\end{array}$ \\
\hline Irisin & $\mathrm{N}$ & $\mathrm{N}$ & Obesity, T2DM \\
\hline Insulin-like growth factor 1 (IGF-1) & $\mathrm{N}$ & $\mathrm{Y}$ & Skeletal muscle growth \\
\hline Interleukin-1 (IL-1) & $\mathrm{N}$ & $\mathrm{N}$ & Chronic inflammation \\
\hline Interleukin-4 (IL-4) & $\mathrm{N}$ & $\mathrm{Y}$ & Anti-inflammatory response \\
\hline Interleukin-6 (IL-6) & $\mathrm{N}$ & $\mathrm{Y}$ & $\begin{array}{l}\text { Gluconeogenesis, cancer, chronic } \\
\text { inflammation }\end{array}$ \\
\hline Interleukin-7 (IL-7) & $\mathrm{Y}$ & $\mathrm{Y}$ & Chronic inflammation \\
\hline Interleukin-8 (IL-8) & $\mathrm{N}$ & $\mathrm{Y}$ & Chronic inflammation \\
\hline Interleukin-10 (IL-10) & $\mathrm{Y}$ & $\mathrm{Y}$ & Anti-inflammatory response \\
\hline Interleukin-15 (IL-15) & $\mathrm{N}$ & $\mathrm{Y}$ & Muscle growth, skin health \\
\hline Interleukin-18 (IL-18) & $\mathrm{N}$ & $\mathrm{Y}$ & Chronic inflammation \\
\hline Interleukin-15 receptor $\alpha$ (IL-15RA) & $\mathrm{Y}$ & $\mathrm{Y}$ & Immunity \\
\hline Leptin (LEP) & $\mathrm{N}$ & $\mathrm{Y}$ & Obesity \\
\hline Leukemia inhibitory factor (LIF) & $\mathrm{Y}$ & $\mathrm{Y}$ & Cancer \\
\hline Meteorin-like protein (METRNL) & $\mathrm{Y}$ & $\mathrm{Y}$ & Obesity, T2DM neurogenesis \\
\hline Myonectin (CTRP15) & $\mathrm{N}$ & $\mathrm{N}$ & Adipose tissue regulation \\
\hline Myostatin (GDF-8) & $\mathrm{N}$ & $\mathrm{N}$ & Muscle growth \\
\hline $\begin{array}{l}\text { Secreted protein acidic and rich in } \\
\text { cysteine (SPARC) }\end{array}$ & $\mathrm{Y}$ & $\mathrm{Y}$ & Cancer \\
\hline $\begin{array}{l}\text { Vascular endothelial growth factor A } \\
\text { (VEGFA) }\end{array}$ & $\mathrm{Y}$ & $\mathrm{Y}$ & Angiogenesis \\
\hline
\end{tabular}

The public databases www.exocarta.org and www.microvesicles.org were searched on November 3, 2016. Eighteen (51\%) of the 35 reported exerkines were listed in www.exocarta.org, and $28(80 \%)$ of the 35 reported exerkines were listed in www .microvesicles.org. Association, Association with a condition or disease in relation to exercise; T2DM, type 2 diabetes mellitus; NAFLD, nonalcoholic fatty liver disease. 


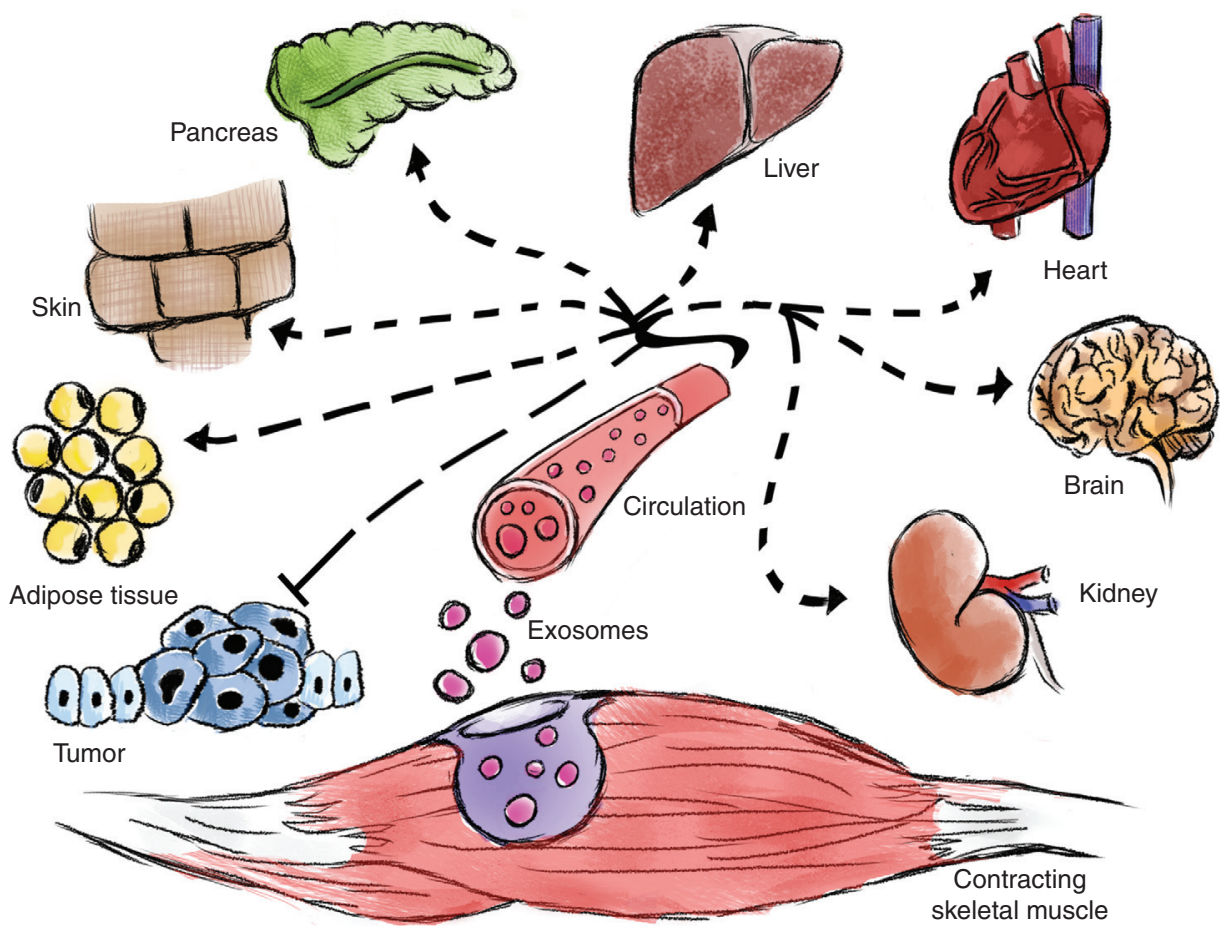

Figure 2. Exosomes promote interorgan cross talk that modulates the systemic benefits of endurance exercise. We hypothesize that the contraction of skeletal muscle during exercise induces the release of exersomes with specific exerkines (peptides, nucleic acids, and lipids) into the blood for interorgan cross talk and mediates the systemic adaptations to endurance exercise.

all-cause mortality have been well established, especially in the areas of obesity, T2DM, cancer, and cardiovascular disease. The support that acute exercise leads to the release of factors from muscle (myokines) and other tissues (exerkines) to orchestrate the multisystemic benefits of exercise are also strongly supported by the literature. The role of exosomes and possibly MVs as intercellular communicators is also very well established in the literature. We have previously hypothesized that exosomes (and possibly MVs) are mediating the interorgan exchange of endocrine-like factors (myokines and exerkines) and represent the true "exercise factors" (Safdar et al. 2016). The scant current data suggests that exosomes and small MVs are released into the circulation in response to acute endurance exercise in an intensity-dependent manner. Many of the currently reported myokines/exerkines have been reported to exist in exosomes/MVs. Finally, exosomes within skel- etal muscle are depleted in response to an acute bout of endurance exercise. Although compelling, the above hypothesis is far from axiomatic or well established, and a number of experiments will be required to conclusively understand the role of exosome and MVs in the acute and chronic response to different modes of exercise and how these relate to the multisystemic benefits of exercise.

There is no doubt that there is a growing interest in the role of exosomes and MVs in biology and medicine, and the application to exercise, although embryonic, is garnering the attention of funding agencies as reflected in the "Molecular Transducers of Physical Activity in Humans" RFA (request for application) issued by the National Institutes of Health (NIH) Common fund. In addition to better understanding the biology of exosomes, MVs, exercise physiology, aging, and the systemic benefits of exercise, it is likely that this area of research will lead to 
therapeutic discovery. Although allogenic exosome transfusions are not likely to be logistically or immunologically viable, it is very possible that combinations of exerkines that are reflective of the molecular patterns associated with the multisystemic benefits of exercise could be given with intermittent subcutaneous injections that mimic the effects of exercise and be independently or adjunctively (e.g., concomitant with insulin) used for patients with T2DM and other morbidities such as obesity, aging-associated sarcopenia, muscular dystrophy, T1DM, and mitochondrial diseases.

\section{ACKNOWLEDGMENTS}

M.A.T. is supported for work on exosomes and exercise with grants from the Canadian Institutes of Health Research (CIHR) and the Natural Sciences and Engineering Research Council (NSERC). A.S. is supported by a CIHR Banting Postdoctoral Fellowship and was the CSO of Exerkine Corporation during part of his tenure doing exercise and exosome research. We thank Ms. Anusheh Saleem for her generous contribution of the original artwork used in this review. M.A.T. is the founder and CEO of Exerkine Corporation, and this company has filed patents for the use of exerkines to treat metabolic disease and the use of exosomes to treat genetic disorders.

\section{REFERENCES}

Adlakha YK, Saini N. 2014. Brain microRNAs and insights into biological functions and therapeutic potential of brain enriched miRNA-128. Mol Cancer 13: 33 .

American Association of Diabetes Education. 2012. Diabetes and physical activity. Diabetes Educ 38: 129-132.

Andrade-Navarro MA, Sanchez-Pulido L, McBride HM. 2009. Mitochondrial vesicles: An ancient process providing new links to peroxisomes. Curr Opin Cell Biol 21: 560-567.

André F, Schartz NE, Chaput N, Flament C, Raposo G, Amigorena S, Angevin E, Zitvogel L. 2002. Tumor-derived exosomes: A new source of tumor rejection antigens. Vaccine 20: A28-A31.

Aoi W, Naito Y, Mizushima K, Takanami Y, Kawai Y, Ichikawa H, Yoshikawa T. 2010. The microRNA miR-696 regulates PGC- $1 \alpha$ in mouse skeletal muscle in response to physical activity. Am J Physiol Endocrinol Metab 298: E799-E806.
Aoi W, Naito Y, Takagi T, Tanimura Y, Takanami Y, Kawai Y, Sakuma K, Hang LP, Mizushima K, Hirai Y, et al. 2013. A novel myokine, secreted protein acidic and rich in cysteine (SPARC), suppresses colon tumorigenesis via regular exercise. Gut 62: 882-889.

Aswad H, Forterre A, Wiklander OP, Vial G, Danty-Berger E, Jalabert A, Lamazière A, Meugnier E, Pesenti S, Ott C, et al. 2014. Exosomes participate in the alteration of muscle homeostasis during lipid-induced insulin resistance in mice. Diabetologia 57: 2155-2164.

Aucher A, Rudnicka D, Davis DM. 2013. MicroRNAs transfer from human macrophages to hepato-carcinoma cells and inhibit proliferation. J Immunol 191: 6250-6260.

Avery L, Flynn D, van Wersch A, Sniehotta FF, Trenell MI. 2012. Changing physical activity behavior in type 2 diabetes: A systematic review and meta-analysis of behavioral interventions. Diabetes Care 35: 2681-2689.

Balbuena L, Casson AG. 2009. Physical activity, obesity and risk for esophageal adenocarcinoma. Future Oncol 5: 1051-1063.

Baranyai T, Herczeg K, Onódi Z, Voszka I, Módos K, Marton N, Nagy G, Mäger I, Wood MJ, El Andaloussi S, et al. 2015. Isolation of exosomes from blood plasma: Qualitative and quantitative comparison of ultracentrifugation and size exclusion chromatography methods. PLOS ONE 10: $\mathrm{e} 0145686$.

Barreiro E, Sznajder JI. 2013. Epigenetic regulation of muscle phenotype and adaptation: A potential role in COPD muscle dysfunction. J Appl Physiol (1985) 114: 12631272.

Belizario JE, Fontes-Oliveira CC, Borges JP, Kashiabara JA, Vannier E. 2016. Skeletal muscle wasting and renewal: A pivotal role of myokine IL-6. Springerplus 5: 619.

Bianco F, Perrotta C, Novellino L, Francolini M, Riganti L, Menna E, Saglietti L, Schuchman EH, Furlan R, Clementi E, et al. 2009. Acid sphingomyelinase activity triggers microparticle release from glial cells. EMBO $J$ 28: 1043-1054.

Bohm CJ, Ho J, Duhamel TA. 2010. Regular physical activity and exercise therapy in end-stage renal disease: How should we move forward? J Nephrol 23: 235-243.

Booth FW, Laye MJ. 2010. The future: Genes, physical activity and health. Acta Physiol (Oxf) 199: 549-556.

Booth AM, Fang Y, Fallon JY, Yang JM, Hildreth JE, Gould SJ. 2006. Exosomes and HIV Gag bud from endosomelike domains of the T cell plasma membrane. J Cell Biol 172: 923-935.

Boström P, Wu J, Jedrychowski MP, Korde A, Ye L, Lo JC, Rasbach KA, Boström EA, Choi JH, Long JZ, et al. 2012. A PGC1- $\alpha$-dependent myokine that drives brown-fatlike development of white fat and thermogenesis. Nature 481: 463-468.

Bouchard C, Blair SN, Katzmarzyk PT. 2015. Less sitting, more physical activity, or higher fitness? Mayo Clin Proc 90: $1533-1540$.

Bourke L, Smith D, Steed L, Hooper R, Carter A, Catto J, Albertsen PC, Tombal B, Payne HA, Rosario DJ. 2016. Exercise for men with prostate cancer: A systematic review and meta-analysis. Eur Urol 69: 693-703. 
Boveris A, Navarro A. 2008. Systemic and mitochondrial adaptive responses to moderate exercise in rodents. Free Radic Biol Med 44: 224-229.

Bramble DM, Lieberman DE. 2004. Endurance running and the evolution of Homo. Nature 432: 345-352.

Brenner I. 2009. Exercise performance by hemodialysis patients: A review of the literature. Phys Sportsmed 37: 8496.

Bronas UG. 2009. Exercise training and reduction of cardiovascular disease risk factors in patients with chronic kidney disease. Adv Chronic Kidney Dis 16: 449-458.

Buchner DM. 2009. Physical activity and prevention of cardiovascular disease in older adults. Clin Geriatr Med 25: 661-675.

Cameron I, Alam MA, Wang J, Brown L. 2012. Endurance exercise in a rat model of metabolic syndrome. Can J Physiol Pharmacol 90: 1490-1497.

Chakravarty EF, Hubert HB, Lingala VB, Fries JF. 2008. Reduced disability and mortality among aging runners: A 21-year longitudinal study. Arch Intern Med 168: 1638 1646.

Chaturvedi P, Kalani A, Medina I, Familtseva A, Tyagi SC. 2015. Cardiosome mediated regulation of MMP9 in diabetic heart: Role of mir29b and mir455 in exercise. J Cell Mol Med 19: 2153-2161.

Chen Y, Verfaillie CM. 2014. MicroRNAs: The fine modulators of liver development and function. Liver Int 34: 976-990.

Choi SB, Jang JS, Hong SM, Jun DW, Park S. 2006. Exercise and dexamethasone oppositely modulate $\beta$-cell function and survival via independent pathways in $90 \%$ pancreatectomized rats. J Endocrinol 190: 471-482.

Choi DS, Kim DK, Kim YK, Gho YS. 2015. Proteomics of extracellular vesicles: Exosomes and ectosomes. Mass Spectrom Rev 34: 474-490.

Cipolletta D, Feuerer M, Li A, Kamei N, Lee J, Shoelson SE, Benoist C, Mathis D. 2012. PPAR- $\gamma$ is a major driver of the accumulation and phenotype of adipose tissue Treg cells. Nature 486: 549-553.

Clark-Matott J, Saleem A, Dai Y, Shurubor Y, Ma X, Safdar A, Beal MF, Tarnopolsky M, Simon DK. 2015. Metabolomic analysis of exercise effects in the POLG mitochondrial DNA mutator mouse brain. Neurobiol Aging 36: 2972-2983.

Covington JD, Tam CS, Bajpeyi S, Galgani JE, Noland RC, Smith SR, Redman LM, Ravussin E. 2016. Myokine expression in muscle and myotubes in response to exercise stimulation. Med Sci Sports Exerc 48: 384-390.

Crane JD, MacNeil LG, Lally JS, Ford RJ, Bujak AL, Brar IK, Kemp BE, Raha S, Steinberg GR, Tarnopolsky MA. 2015 Exercise-stimulated interleukin-15 is controlled by AMPK and regulates skin metabolism and aging. Aging Cell 14: 625-634.

Deatherage BL, Cookson BT. 2012. Membrane vesicle release in bacteria, eukaryotes, and archaea: A conserved yet underappreciated aspect of microbial life. Infect Immun 80: 1948-1957.

Dela F, Ploug T, Handberg A, Petersen LN, Larsen JJ, Mikines KJ, Galbo H. 1994. Physical training increases muscle GLUT4 protein and mRNA in patients with NIDDM. Diabetes 43: 862-865.
Demontis F, Piccirillo R, Goldberg AL, Perrimon N. 2013. The influence of skeletal muscle on systemic aging and lifespan. Aging Cell 12: 943-949.

Deng ZB, Poliakov A, Hardy RW, Clements R, Liu C, Liu Y, Wang J, Xiang X, Zhang S, Zhuang X, et al. 2009. Adipose tissue exosome-like vesicles mediate activation of macrophage-induced insulin resistance. Diabetes 58: $2498-$ 2505.

Devries MC, Samjoo IA, Hamadeh MJ, McCready C, Raha S, Watt MJ, Steinberg GR, Tarnopolsky MA. 2013. Endurance training modulates intramyocellular lipid compartmentalization and morphology in skeletal muscle of lean and obese women. J Clin Endocrinol Metab 98: $4852-4862$.

Diabetes Prevention Program Research Group; Knowler WC, Fowler SE, Hamman RF, Christophi CA, Hoffman HJ, Brenneman AT, Brown-Friday JO, Goldberg R, Venditti E, et al. 2009. 10-year follow-up of diabetes incidence and weight loss in the Diabetes Prevention Program Outcomes Study. Lancet 374: 1677-1686.

Di Francescomarino S, Sciartilli A, Di Valerio V, Di Baldassarre A, Gallina S. 2009. The effect of physical exercise on endothelial function. Sports Med 39: 797-812.

Di Raimondo D, Tuttolomondo A, Musiari G, Schimmenti C, D'Angelo A, Pinto A. 2016. Are the myokines the mediators of physical activity-induced health benefits? Curr Pharm Des 22: 3622-3647.

Dutheil F, Lac G, Lesourd B, Chapier R, Walther G, Vinet A, Sapin V, Verney J, Ouchchane L, Duclos M, et al. 2013. Different modalities of exercise to reduce visceral fat mass and cardiovascular risk in metabolic syndrome: The RESOLVE randomized trial. Int J Cardiol 168: 3634-3642.

Earnest CP, Lupo M, Thibodaux J, Hollier C, Butitta B, Lejeune E, Johannsen NM, Gibala MJ, Church TS. 2013. Interval training in men at risk for insulin resistance. Int J Sports Med 34: 355-363.

El-Andaloussi S, Lee Y, Lakhal-Littleton S, Li J, Seow Y, Gardiner C, Alvarez-Erviti L, Sargent IL, Wood MJ. 2012. Exosome-mediated delivery of siRNA in vitro and in vivo. Nat Protoc 7: 2112-2126.

Espeland MA, Glick HA, Bertoni A, Brancati FL, Bray GA, Clark JM, Curtis JM, Egan C, Evans M, Foreyt JP, et al. 2014. Impact of an intensive lifestyle intervention on use and cost of medical services among overweight and obese adults with type 2 diabetes: The action for health in diabetes. Diabetes Care 37: 2548-2556.

Esquilin Y, Queenan C, Calabro A, Leonardi D. 2012. mtDNA migration and the role of exosomes in horizontal gene transfer. Microsc Microanal 18: 286-287.

Fernandez-Hernando C, Baldan A. 2013. MicroRNAs and cardiovascular disease. Curr Genet Med Rep 1: 30-38.

Ferrante SC, Nadler EP, Pillai DK, Hubal MJ, Wang Z, Wang JM, Gordish-Dressman H, Koeck E, Sevilla S, Wiles AA, et al. 2015. Adipocyte-derived exosomal miRNAs: A novel mechanism for obesity-related disease. Pediatr Res 77: $447-454$.

Filios SR, Shalev A. 2015. $\beta$-cell microRNAs: Small but powerful. Diabetes 64: 3631-644.

Fisher FM, Kleiner S, Douris N, Fox EC, Mepani RJ, Verdeguer F, Wu J, Kharitonenkov A, Flier JS, Maratos-Flier E, et al. 2012. FGF21 regulates PGC-1 $\alpha$ and browning of 
white adipose tissues in adaptive thermogenesis. Genes Dev 26: $271-281$.

Florholmen G, Thoresen GH, Rustan AC, Jensen J, Christensen G, Aas V. 2006. Leukaemia inhibitory factor stimulates glucose transport in isolated cardiomyocytes and induces insulin resistance after chronic exposure. Diabetologia 49: 724-731.

Fong DY, Ho JW, Hui BP, Lee AM, Macfarlane DJ, Leung SS, Cerin E, Chan WY, Leung IP, Lam SH, et al. 2012. Physical activity for cancer survivors: Meta-analysis of randomised controlled trials. BMJ 344: e70.

Forterre A, Jalabert A, Berger E, Baudet M, Chikh K, Errazuriz E, De Larichaudy J, Chanon S, Weiss-Gayet M, Hesse AM, et al. 2014. Proteomic analysis of C2C12 myoblast and myotube exosome-like vesicles: A new paradigm for myoblast-myotube cross talk? PLoS ONE 9: e84153.

Friedenreich CM, Neilson HK, Farris MS, Courneya KS. 2016. Physical activity and cancer outcomes: A precision medicine approach. Clin Cancer Res 22: 4766-4775.

Fruhbeis C, Helmig S, Tug S, Simon P, Kramer-Albers EM. 2015. Physical exercise induces rapid release of small extracellular vesicles into the circulation. J Extracell Vesicles 4: 28239.

Gong Z, Hong CC, Bandera EV, Adams-Campbell LL, Troester MA, Park SY, McInerney KA, Zirpoli G, Olshan AF, Palmer JR, et al. 2016. Vigorous physical activity and risk of breast cancer in the African American breast cancer epidemiology and risk consortium. Breast Cancer Res Treat 159: 347-356.

Granjon A, Gustin MP, Rieusset J, Lefai E, Meugnier E, Güller I, Cerutti C, Paultre C, Disse E, Rabasa-Lhoret $\mathrm{R}$, et al. 2009. The microRNA signature in response to insulin reveals its implication in the transcriptional action of insulin in human skeletal muscle and the role of a sterol regulatory element-binding protein-1c/myocyte enhancer factor 2C pathway. Diabetes 58: 2555-2564.

Gray MW. 1989. The evolutionary origins of organelles. Trends Genet 5: 294-299.

Gregor MF, Hotamisligil GS. 2011. Inflammatory mechanisms in obesity. Annu Rev Immunol 29: 415-445.

Gregory SM, Spiering BA, Alemany JA, Tuckow AP, Rarick KR, Staab JS, Hatfield DL, Kraemer WJ, Maresh CM, Nindl BC. 2013. Exercise-induced insulin-like growth factor I system concentrations after training in women. Med Sci Sports Exerc 45: 420-428.

Greiwe JS, Holloszy JO, Semenkovich CF. 2000. Exercise induces lipoprotein lipase and GLUT-4 protein in muscle independent of adrenergic-receptor signaling. J Appl Physiol (1985) 89: 176-181.

Gulve EA, Spina RJ. 1995. Effect of 7-10 days of cycle ergometer exercise on skeletal muscle GLUT-4 protein content. J Appl Physiol (1985) 79: 1562-1566.

Hagiwara K, Ochiya T, Kosaka N. 2014. A paradigm shift for extracellular vesicles as small RNA carriers: From cellular waste elimination to therapeutic applications. Drug Deliv Transl Res 4: 31-37.

Hållmarker U, James S, Michaëlsson K, Ärnlöv J, Sandin F, Holmberg L. 2015. Cancer incidence in participants in a long-distance ski race (Vasaloppet, Sweden) compared to the background population. Eur J Cancer 51: 558-568.
Hansen JS, Clemmesen JO, Secher NH, Hoene M, Drescher A, Weigert C, Pedersen BK, Plomgaard P. 2015. Glucagon-to-insulin ratio is pivotal for splanchnic regulation of FGF-21 in humans. Mol Metab 4: 551-560.

Harding C, Heuser J, Stahl P. 1983. Receptor-mediated endocytosis of transferrin and recycling of the transferrin receptor in rat reticulocytes. J Cell Biol 97: 329-339.

Harding CV, Heuser JE, Stahl PD. 2013. Exosomes: Looking back three decades and into the future. J Cell Biol 200: 367-371.

Harris E, Rakobowchuk M, Birch KM. 2014. Sprint interval and sprint continuous training increases circulating $\mathrm{CD} 34+$ cells and cardio-respiratory fitness in young healthy women. PLOS ONE 9: e108720.

Hawley JA. 2004. Exercise as a therapeutic intervention for the prevention and treatment of insulin resistance. Diabetes Metab Res Rev 20: 383-393.

Helmig S, Fruhbeis C, Kramer-Albers EM, Simon P, Tug S. 2015. Release of bulk cell free DNA during physical exercise occurs independent of extracellular vesicles. Eur $J$ Appl Physiol 115: 2271-2280.

Helmrich SP, Ragland DR, Leung RW, Paffenbarger RS Jr. 1991. Physical activity and reduced occurrence of noninsulin-dependent diabetes mellitus. $N$ Engl J Med 325: $147-152$.

Henstridge DC, Bruce CR, Drew BG, Tory K, Kolonics A, Estevez E, Chung J, Watson N, Gardner T, Lee-Young RS, et al. 2014. Activating HSP72 in rodent skeletal muscle increases mitochondrial number and oxidative capacity and decreases insulin resistance. Diabetes 63: 1881-1894.

Herring MP, O'Connor PJ, Dishman RK. 2010. The effect of exercise training on anxiety symptoms among patients: A systematic review. Arch Intern Med 170: 321-331.

Hetzler KL, Hardee JP, Puppa MJ, Narsale AA, Sato S, Davis JM, Carson JA. 2015. Sex differences in the relationship of IL-6 signaling to cancer cachexia progression. Biochim Biophys Acta 1852: 816-825.

Hood DA. 2001. Invited review: Contractile activity-induced mitochondrial biogenesis in skeletal muscle. $J$ Appl Physiol (1985) 90: 1137-1157.

Hoppeler H, Baum O, Lurman G, Mueller M. 2011. Molecular mechanisms of muscle plasticity with exercise. Compr Physiol 1: 1383-1412.

Hoshino A, Costa-Silva B, Shen TL, Rodrigues G, Hashimoto A, Tesic Mark M, Molina H, Kohsaka S, Di Giannatale A, Ceder S, et al. 2015. Tumour exosome integrins determine organotropic metastasis. Nature 527: 329 335.

Hubal MJ, Nadler EP, Ferrante SC, Barberio MD, Suh JH, Wang J, Dohm GL, Pories WJ, Mietus-Snyder M, Freishtat RJ. 2016. Circulating adipocyte-derived exosomal MicroRNAs associated with decreased insulin resistance after gastric bypass. Obesity (Silver Spring) 25: 102-110.

Hwang I. 2013. Cell-cell communication via extracellular membrane vesicles and its role in the immune response. Mol Cells 36: 105-111.

Januszyk K, Lima CD. 2004. The eukaryotic RNA exosome. Curr Opin Struct Biol 24: 132-140.

Joanisse S, Parise G. 2016. Cytokine mediated control of muscle stem cell function. Adv Exp Med Biol 900: 27-44. 
Joseph AM, Hood DA. 2014. Relationships between exercise, mitochondrial biogenesis and type 2 diabetes. Med Sport Sci 60: 48-61.

Kajimura S, Spiegelman BM, Seale P. 2015. Brown and beige fat: Physiological roles beyond heat generation. Cell Metab 22: 546-559.

Kalani A, Tyagi A, Tyagi N. 2014. Exosomes: Mediators of neurodegeneration, neuroprotection and therapeutics. Mol Neurobiol 49: 590-600.

Katzmarzyk PT, Janssen I. 2004. The economic costs associated with physical inactivity and obesity in Canada: An update. Can J Appl Physiol 29: 90-115.

Katzmarzyk PT, Gledhill N, Shephard RJ. 2000. The economic burden of physical inactivity in Canada. CMAJ 163: $1435-1440$

Knowler WC, Barrett-Connor E, Fowler SE, Hamman RF, Lachin JM, Walker EA, Nathan DM; Diabetes Prevention Program Research Group. 2002. Reduction in the incidence of type 2 diabetes with lifestyle intervention or metformin. N Engl J Med 346: 393-403.

Koeck ES, Iordanskaia T, Sevilla S, Ferrante SC, Hubal MJ, Freishtat RJ, Nadler EP. 2014. Adipocyte exosomes induce transforming growth factor $\beta$ pathway dysregulation in hepatocytes: A novel paradigm for obesity-related liver disease. J Surg Res 192: 268-275.

Kolesar JE, Safdar A, Abadi A, MacNeil LG, Crane JD, Tarnopolsky MA, Kaufman BA. 2014. Defects in mitochondrial DNA replication and oxidative damage in muscle of mtDNA mutator mice. Free Radic Biol Med 75: 241-251.

Kosmadakis GC, Bevington A, Smith AC, Clapp EL, Viana JL, Bishop NC, Feehally J. 2010. Physical exercise in patients with severe kidney disease. Nephron Clin Pract 115: c7-c16.

Kruk J. 2009. Physical activity and health. Asian Pac J Cancer Prev 10: 721-728.

Kulp A, Kuehn MJ. 2010. Biological functions and biogenesis of secreted bacterial outer membrane vesicles. Annu Rev Microbiol 64: 163-184.

Kuppusamy KT, Sperber H, Ruohola-Baker H. 2013. MicroRNA regulation and role in stem cell maintenance, cardiac differentiation and hypertrophy. Curr Mol Med 13: $757-764$.

Lachenal G, Pernet-Gallay K, Chivet M, Hemming FJ, Belly A, Bodon G, Blot B, Haase G, Goldberg Y, Sadoul R. 2011. Release of exosomes from differentiated neurons and its regulation by synaptic glutamatergic activity. Mol Cell Neurosci 46: 409-418.

Lancaster GI, Febbraio MA. 2005a. Mechanisms of stressinduced cellular HSP72 release: Implications for exerciseinduced increases in extracellular HSP72. Exerc Immunol Rev 11: 46-52.

Lancaster GI, Febbraio MA. 2005b. Exosome-dependent trafficking of HSP70: A novel secretory pathway for cellular stress proteins. J Biol Chem 280: 23349-23355.

Langin D. 2010. Recruitment of brown fat and conversion of white into brown adipocytes: Strategies to fight the metabolic complications of obesity? Biochim Biophys Acta 1801: 372-376.

Lansford KA, Shill DD, Dicks AB, Marshburn MP, Southern WM, Jenkins NT. 2016. Effect of acute exercise on circu- lating angiogenic cell and microparticle populations. Exp Physiol 101: 155-167.

Lauritzen HP, Brandauer J, Schjerling P, Koh HJ, Treebak JT, Hirshman MF, Galbo H, Goodyear LJ. 2013. Contraction and AICAR stimulate IL-6 vesicle depletion from skeletal muscle fibers in vivo. Diabetes 62: 3081-3092.

Lazar I, Clement E, Dauvillier S, Milhas D, Ducoux-Petit M, LeGonidec S, Moro C, Soldan V, Dalle S, Balor S, et al. 2016. Adipocyte exosomes promote melanoma aggressiveness through fatty acid oxidation: A novel mechanism linking obesity and cancer. Cancer Res 76: 4051-4057.

Lee EY, Choi DY, Kim DK, Kim JW, Park JO, Kim S, Kim SH, Desiderio DM, Kim YK, Kim KP, et al. 2009. Gram-positive bacteria produce membrane vesicles: Proteomicsbased characterization of Staphylococcus aureus-derived membrane vesicles. Proteomics 9: 5425-5436.

Lee AH, Su D, Pasalich M, Wong YL, Binns CW. 2013. Habitual physical activity reduces risk of ovarian cancer: A case-control study in southern China. Prev Med 57: S31S33.

Lee P, Linderman JD, Smith S, Brychta RJ, Wang J, Idelson C, Perron RM, Werner CD, Phan GQ, Kammula US, et al. 2014. Irisin and FGF21 are cold-induced endocrine activators of brown fat function in humans. Cell Metab 19: 302-309.

Lin J, Tarr PT, Yang R, Rhee J, Puigserver P, Newgard CB, Spiegelman BM. 2003. PGC-1 $\beta$ in the regulation of hepatic glucose and energy metabolism. J Biol Chem 278: 30843-30848.

Lin Y, Gajewski A, Poznanska A. 2016. Examining mortality risk and rate of ageing among Polish Olympic athletes: A survival follow-up from 1924 to 2012. BMJ Open 6: e010965.

Little JP, Safdar A, Benton CR, Wright DC. 2011a. Skeletal muscle and beyond: The role of exercise as a mediator of systemic mitochondrial biogenesis. Appl Physiol Nutr Metab 36: 598-607.

Little JP, Safdar A, Bishop D, Tarnopolsky MA, Gibala MJ. 2011b. An acute bout of high-intensity interval training increases the nuclear abundance of PGC- $1 \alpha$ and activates mitochondrial biogenesis in human skeletal muscle. Am J Physiol Regul Integr Comp Physiol 300: R1303-R1310.

Little JP, Gillen JB, Percival ME, Safdar A, Tarnopolsky MA, Punthakee Z, Jung ME, Gibala MJ. 2011c. Low-volume high-intensity interval training reduces hyperglycemia and increases muscle mitochondrial capacity in patients with type 2 diabetes. J Appl Physiol (1985) 111: 15541560.

Lo KA, Sun L. 2013. Turning WAT into BAT: A review on regulators controlling the browning of white adipocytes. Biosci Rep 33: e00065.

Look AHEAD Research Group; Wing RR, Bolin P, Brancati FL, Bray GA, Clark JM, Coday M, Crow RS, Curtis JM, Egan CM, et al. 2013. Cardiovascular effects of intensive lifestyle intervention in type 2 diabetes. N Engl J Med 369: $145-154$.

Look AHEAD Research Group. 2014. Effect of a long-term behavioural weight loss intervention on nephropathy in overweight or obese adults with type 2 diabetes: A secondary analysis of the Look AHEAD randomised clinical trial. Lancet Diabetes Endocrinol 2: 801-809. 
Lopez-Otin C, Blasco MA, Partridge L, Serrano M, Kroemer G. 2013. The hallmarks of aging. Cell 153: 1194-1217.

Lötvall J, Hill AF, Hochberg F, Buzás EI, Di Vizio D, Gardiner C, Gho YS, Kurochkin IV, Mathivanan S, Quesenberry P, et al. 2014. Minimal experimental requirements for definition of extracellular vesicles and their functions: A position statement from the International Society for Extracellular Vesicles. J Extracell Vesicles 3: 26913.

Lowell BB, Shulman GI. 2005. Mitochondrial dysfunction and type 2 diabetes. Science 307: 384-387.

Margolis LM, Lessard SJ, Ezzyat Y, Fielding RA, Rivas DA. 2016. Circulating microRNA are predictive of aging and acute adaptive response to resistance exercise in men. $J$ Gerontol A Biol Sci Med Sci doi: 10.1093/gerona/glw243.

Mathivanan S, Simpson RJ. 2009. ExoCarta: A compendium of exosomal proteins and RNA. Proteomics 9: 4997-5000.

Mathivanan S, Ji H, Simpson RJ. 2010. Exosomes: Extracellular organelles important in intercellular communication. J Proteomics 73: 1907-1920.

Mathur N, Pedersen BK. 2008. Exercise as a mean to control low-grade systemic inflammation. Mediators Inflamm 2008: 109502.

Matthews VB, Aström MB, Chan MH, Bruce CR, Krabbe KS, Prelovsek O, Akerström T, Yfanti C, Broholm C, Mortensen OH, et al. 2009. Brain-derived neurotrophic factor is produced by skeletal muscle cells in response to contraction and enhances fat oxidation via activation of AMP-activated protein kinase. Diabetologia 52: 14091418.

McBroom AJ, Johnson AP, Vemulapalli S, Kuehn MJ. 2006. Outer membrane vesicle production by Escherichia coli is independent of membrane instability. J Bacteriol 188: 5385-5392.

McLean CS, Mielke C, Cordova JM, Langlais PR, Bowen B, Miranda D, Coletta DK, Mandarino LJ. 2015. Gene and microRNA expression responses to exercise; relationship with insulin sensitivity. PLoS ONE 10: e0127089.

McLelland GL, Soubannier V, Chen CX, McBride HM, Fon EA. 2014. Parkin and PINK1 function in a vesicular trafficking pathway regulating mitochondrial quality control. EMBO J 33: 282-295.

Mendis S, Davis S, Norrving B. 2015. Organizational update: The World Health Organization Global Status Report on Noncommunicable Diseases 2014; one more landmark step in the combat against stroke and vascular disease. Stroke 46: e121-e122.

Mohajeri Tehrani MR, Tajvidi M, Kahrizi S, Hedayati M. 2015. Does endurance training affect IGF-1/IGFBP-3 and insulin sensitivity in patients with type 2 diabetes? J Sports Med Phys Fitness 55: 1004-1012.

Mohan S, Wergedal JE, Das S, Kesavan C. 2015. Conditional disruption of miR17-92 cluster in collagen type I-producing osteoblasts results in reduced periosteal bone formation and bone anabolic response to exercise. Physiol Genomics 47: 33-43.

Moon HY, Becke A, Berron D, Becker B, Sah N, Benoni G, Janke E, Lubejko ST, Greig NH, Mattison JA, et al. 2016. Running-induced systemic cathepsin B secretion is associated with memory function. Cell Metab 24: 332-340.

Moore SC, Lee IM, Weiderpass E, Campbell PT, Sampson JN, Kitahara CM, Keadle SK, Arem H, Berrington de
Gonzalez A, Hartge P, et al. 2016. Association of leisure-time physical activity with risk of 26 types of cancer in 1.44 million adults. JAMA Intern Med 176: 816-825.

Mooren FC, Viereck J, Kruger K, Thum T. 2014. Circulating microRNAs as potential biomarkers of aerobic exercise capacity. Am J Physiol Heart Circ Physiol 306: H557H563.

Mootha VK, Lindgren CM, Eriksson KF, Subramanian A, Sihag S, Lehar J, Puigserver P, Carlsson E, Ridderstråle M, Laurila E, et al. 2003. PGC-1 $\alpha$-responsive genes involved in oxidative phosphorylation are coordinately downregulated in human diabetes. Nat Genet 34: 267-273.

Morino K, Petersen KF, Dufour S, Befroy D, Frattini J, Shatzkes N, Neschen S, White MF, Bilz S, Sono S, et al. 2005. Reduced mitochondrial density and increased IRS1 serine phosphorylation in muscle of insulin-resistant offspring of type 2 diabetic parents. J Clin Invest 115: 3587-3593.

Morino K, Petersen KF, Shulman GI. 2006. Molecular mechanisms of insulin resistance in humans and their potential links with mitochondrial dysfunction. Diabetes 55: S9-S15.

Mulcahy LA, Pink RC, Carter DR. 2014. Routes and mechanisms of extracellular vesicle uptake. J Extracell Vesicles doi: 10.3402/jev.v3.24641.

Muroya S, Shibata M, Hayashi M, Oe M, Ojima K. 2016. Differences in circulating microRNAs between grazing and grain-fed wagyu cattle are associated with altered expression of intramuscular microRNA, the potential target PTEN, and lipogenic genes. PLoS ONE 11: e0162496.

Nader GA, Lundberg IE. 2009. Exercise as an anti-inflammatory intervention to combat inflammatory diseases of muscle. Curr Opin Rheumatol 21: 599-603.

Neidert LE, Mobley CB, Kephart WC, Roberts MD, Kluess HA. 2016. The serine protease, dipeptidyl peptidase IV as a myokine: Dietary protein and exercise mimetics as a stimulus for transcription and release. Physiol Rep 4: e12827.

Nielsen S, Scheele C, Yfanti C, Akerström T, Nielsen AR, Pedersen BK, Laye MJ. 2010. Muscle specific microRNAs are regulated by endurance exercise in human skeletal muscle. J Physiol 588: 4029-4037.

Nielsen S, Hvid T, Kelly M, Lindegaard B, Dethlefsen C, Winding K, Mathur N, Scheele C, Pedersen BK, Laye MJ. 2014a. Muscle specific miRNAs are induced by testosterone and independently upregulated by age. Front Physiol 4: 394.

Nielsen S, Åkerström T, Rinnov A, Yfanti C, Scheele C, Pedersen BK, Laye MJ. 2014b. The miRNA plasma signature in response to acute aerobic exercise and endurance training. PLoS ONE 9: e87308.

Ojima KO, Oe M, Nakajimaa I, Shibatab M, Chikunia K, Muroyaa S, Nishimurac T. 2014. Proteomic analysis of secreted proteins from skeletal muscle cells during differentiation. EuPA Open Proteomics 5: 1-9.

Ooi JY, Bernardo BC, McMullen JR. 2014. The therapeutic potential of miRNAs regulated in settings of physiological cardiac hypertrophy. Future Med Chem 6: 205-222.

Pan BT, Johnstone RM. 1983. Fate of the transferrin receptor during maturation of sheep reticulocytes in vitro: Selective externalization of the receptor. Cell 33: 967-978. 
Párrizas M, Brugnara L, Esteban Y, González-Franquesa A Canivell S, Murillo S, Gordillo-Bastidas E, Cussó R, Cadefau JA, García-Roves PM, et al. 2015. Circulating miR192 and miR-193b are markers of prediabetes and are modulated by an exercise intervention. J Clin Endocrinol Metab 100: E407-E415.

Parsons TL, King-Vanvlack CE. 2009. Exercise and end-stage kidney disease: Functional exercise capacity and cardiovascular outcomes. Adv Chronic Kidney Dis 16: 459-481.

Pedersen BK. 2007. IL-6 signalling in exercise and disease. Biochem Soc Trans 35: 1295-1297.

Pedersen BK. 2009a. The diseasome of physical inactivityand the role of myokines in muscle-fat cross talk. J Physiol 587: 5559-5568.

Pedersen BK. 2009b. Edward F. Adolph distinguished lecture: Muscle as an endocrine organ: IL-6 and other myokines. J Appl Physiol (1985) 107: 1006-1014.

Pedersen BK. 2011. Muscles and their myokines. J Exp Biol 214: $337-346$.

Pedersen BK, Febbraio MA. 2012. Muscles, exercise and obesity: Skeletal muscle as a secretory organ. Nat Rev Endocrinol 8: 457-465.

Pedersen BK, Fischer CP. 2007a. Physiological roles of muscle-derived interleukin-6 in response to exercise. Cur Opin Clin Nutr Metab Care 10: 265-271.

Pedersen BK, Fischer CP. 2007b. Beneficial health effects of exercise-the role of IL-6 as a myokine. Trends Pharmacol Sci 28: 152-156.

Pedersen L, Hojman P. 2012. Muscle-to-organ cross talk mediated by myokines. Adipocyte 1: 164-167.

Petersen KF, Shulman GI. 2006. Etiology of insulin resistance. Am J Med 119: S10-S16.

Pedersen BK, Steensberg A, Fischer C, Keller C, Keller P, Plomgaard P, Febbraio M, Saltin B. 2003. Searching for the exercise factor: Is IL-6 a candidate? J Muscle Res Cell Motil 24: 113-119.

Pedersen BK, Steensberg A, Fischer C, Keller C, Keller P, Plomgaard P, Wolsk-Petersen E, Febbraio M. 2004. The metabolic role of IL-6 produced during exercise: Is IL-6 an exercise factor? Proc Nutr Soc 63: 263-267.

Pedersen L, Idorn M, Olofsson GH, Lauenborg B, Nookaew I, Hansen RH, Johannesen HH, Becker JC, Pedersen KS, Dethlefsen C, et al. 2016. Voluntary running suppresses tumor growth through epinephrine- and IL-6-dependent NK cell mobilization and redistribution. Cell Metab 23: $554-562$.

Phillips SM, Han XX, Green HJ, Bonen A. 1996. Increments in skeletal muscle GLUT-1 and GLUT-4 after endurance training in humans. Am J Physiol 270: E456-E462.

Pilegaard H, Saltin B, Neufer PD. 2003. Exercise induces transient transcriptional activation of the PGC- $1 \alpha$ gene in human skeletal muscle. J Physiol 546: 851-858.

Pope SM, Lässer C. 2013. Toxoplasma gondii infection of fibroblasts causes the production of exosome-like vesicles containing a unique array of mRNA and miRNA transcripts compared to serum starvation. J Extracell Vesicles doi: $10.3402 /$ jev.v2i0.22484

Puigserver P, Wu Z, Park CW, Graves R, Wright M, Spiegelman BM. 1998. A cold-inducible coactivator of nuclear receptors linked to adaptive thermogenesis. Cell 92: 829839.
Radom-Aizik S, Zaldivar F Jr, Leu SY, Adams GR, Oliver S, Cooper DM. 2012. Effects of exercise on microRNA expression in young males peripheral blood mononuclear cells. Clin Transl Sci 5: 32-38.

Ramakrishnaiah V, Thumann C, Fofana I, Habersetzer F, Pan Q, de Ruiter PE, Willemsen R, Demmers JA, Stalin Raj V, Jenster G, et al. 2013. Exosome-mediated transmission of hepatitis $\mathrm{C}$ virus between human hepatoma Huh7.5 cells. Proc Natl Acad Sci 110: 13109-13113.

Rao RR, Long JZ, White JP, Svensson KJ, Lou J, Lokurkar I, Jedrychowski MP, Ruas JL, Wrann CD, Lo JC, et al. 2014. Meteorin-like is a hormone that regulates immune-adipose interactions to increase beige fat thermogenesis. Cell 157: 1279-1291.

Raposo G, Stoorvogel W. 2013. Extracellular vesicles: Exosomes, microvesicles, and friends. J Cell Biol 200: $373-$ 383.

Record M, Carayon K, Poirot M, Silvente-Poirot S. 2014. Exosomes as new vesicular lipid transporters involved in cell-cell communication and various pathophysiologies. Biochim Biophys Acta 1841: 108-120.

Ren JM, Semenkovich CF, Gulve EA, Gao J, Holloszy JO. 1994. Exercise induces rapid increases in GLUT4 expression, glucose transport capacity, and insulin-stimulated glycogen storage in muscle. J Biol Chem 269: $14396-$ 14401.

Rider MA, Hurwitz SN, Meckes DG Jr. 2016. ExtraPEG: A polyethylene glycol-based method for enrichment of extracellular vesicles. Sci Rep 6: 23978.

Ritov VB, Menshikova EV, Azuma K, Wood R, Toledo FG, Goodpaster BH, Ruderman NB, Kelley DE. 2010. Deficiency of electron transport chain in human skeletal muscle mitochondria in type 2 diabetes mellitus and obesity. Am J Physiol Endocrinol Metab 298: E49-E58.

Rivera J, Cordero RJ, Nakouzi AS, Frases S, Nicola A, Casadevall A. 2010. Bacillus anthracis produces membranederived vesicles containing biologically active toxins. Proc Natl Acad Sci 107: 19002-19007.

Romao JM, Jin W, He M, McAllister T, Guan le L. 2014. MicroRNAs in bovine adipogenesis: Genomic context, expression and function. BMC Genomics 15: 137.

Rubin RR, Wadden TA, Bahnson JL, Blackburn GL, Brancati FL, Bray GA, Coday M, Crow SJ, Curtis JM, Dutton G, et al. 2014. Impact of intensive lifestyle intervention on depression and health-related quality of life in type 2 diabetes: The Look AHEAD Trial. Diabetes Care 37: 15441553.

Russell AP, Lamon S, Boon H, Wada S, Güller I, Brown EL, Chibalin AV, Zierath JR, Snow RJ, Stepto N, et al. 2013 Regulation of miRNAs in human skeletal muscle following acute endurance exercise and short-term endurance training. J Physiol 591: 4637-4653.

Safdar A, Abadi A, Akhtar M, Hettinga BP, Tarnopolsky MA. 2009. miRNA in the regulation of skeletal muscle adaptation to acute endurance exercise in $\mathrm{C} 57 \mathrm{Bl} / 6 \mathrm{~J}$ male mice. PLoS ONE 4: e5610.

Safdar A, Bourgeois JM, Ogborn DI, Little JP, Hettinga BP, Akhtar M, Thompson JE, Melov S, Mocellin NJ, Kujoth GC, et al. 2011a. Endurance exercise rescues progeroid aging and induces systemic mitochondrial rejuvenation in mtDNA mutator mice. Proc Natl Acad Sci 108: 4135 4140. 
Safdar A, Little JP, Stokl AJ, Hettinga BP, Akhtar M, Tarnopolsky MA. 2011b. Exercise increases mitochondrial PGC-1 $\alpha$ content and promotes nuclear-mitochondrial cross talk to coordinate mitochondrial biogenesis. J Biol Chem 286: 10605-10617.

Safdar A, Khrapko K, Flynn JM, Saleem A, De Lisio M, Johnston AP, Kratysberg Y, Samjoo IA, Kitaoka Y, Ogborn DI, et al. 2015. Exercise-induced mitochondrial p53 repairs mtDNA mutations in mutator mice. Skelet Muscle 6: 7 .

Safdar A, Saleem A, Tarnopolsky MA. 2016. The potential of endurance exercise-derived exosomes to treat metabolic diseases. Nat Rev Endocrinol 12: 504-517.

Samjoo IA, Safdar A, Hamadeh MJ, Raha S, Tarnopolsky MA. 2013. The effect of endurance exercise on both skeletal muscle and systemic oxidative stress in previously sedentary obese men. Nutr Diabetes 3: e88.

Savina A, Fader CM, Damiani MT, Colombo MI. 2005. Rab11 promotes docking and fusion of multivesicular bodies in a calcium-dependent manner. Traffic 6: 131143.

Sawada N, Jiang A, Takizawa F, Safdar A, Manika A, Tesmenitsky Y, Kang KT, Bischoff J, Kalwa H, Sartoretto JL, et al. 2014. Endothelial PGC- $1 \alpha$ mediates vascular dysfunction in diabetes. Cell Metab 19: 246-258.

Schnohr P, O’Keefe JH, Marott JL, Lange P, Jensen GB. 2015. Dose of jogging and long-term mortality: The Copenhagen City Heart Study. J Am Coll Cardiol 65: 411-419.

Seldin MM, Peterson JM, Byerly MS, Wei Z, Wong GW. 2012. Myonectin (CTRP15), a novel myokine that links skeletal muscle to systemic lipid homeostasis. J Biol Chem 287: 11968-11980.

Seldin MM, Lei X, Tan SY, Stanson KP, Wei Z, Wong GW. 2013. Skeletal muscle-derived myonectin activates the mammalian target of rapamycin (mTOR) pathway to suppress autophagy in liver. J Biol Chem 288: 3607336082.

Sell H, Eckel J. 2009. Chemotactic cytokines, obesity and type 2 diabetes: In vivo and in vitro evidence for a possible causal correlation? Proc Nutr Soc 68: 378-384.

Sethupathy P. 2016. The promise and challenge of therapeutic microRNA silencing in diabetes and metabolic diseases. Curr Diab Rep 16: 52.

Simoneau JA, Colberg SR, Thaete FL, Kelley DE. 1995. Skeletal muscle glycolytic and oxidative enzyme capacities are determinants of insulin sensitivity and muscle composition in obese women. FASEB J 9: 273-278.

Skokos D, Botros HG, Demeure C, Morin J, Peronet R, Birkenmeier G, Boudaly S, Mécheri S. 2003. Mast cellderived exosomes induce phenotypic and functional maturation of dendritic cells and elicit specific immune responses in vivo. J Immunol 170: 3037-3045.

Soekmadji C, Russell PJ, Nelson CC. 2013. Exosomes in prostate cancer: Putting together the pieces of a puzzle. Cancers (Basel) 5: 1522-1544.

Sokolova V, Ludwig AK, Hornung S, Rotan O, Horn PA, Epple M, Giebel B. 2011. Characterisation of exosomes derived from human cells by nanoparticle tracking analysis and scanning electron microscopy. Colloids Surf B Biointerfaces 87: 146-150.
Soubannier V, McLelland GL, Zunino R, Braschi E, Rippstein P, Fon EA, McBride HM. 2012. Avesicular transport pathway shuttles cargo from mitochondria to lysosomes. Curr Biol 22: 135-141.

Stanford KI, Middelbeek RJ, Townsend KL, Lee MY, Takahashi H, So K, Hitchcox KM, Markan KR, Hellbach K, Hirshman MF, et al. 2015. A novel role for subcutaneous adipose tissue in exercise-induced improvements in glucose homeostasis. Diabetes 64: 2002-2014.

Stuart M, Chard S, Benvenuti F, Steinwachs S. 2009. Community exercise: A vital component to healthy aging. Healthc Pap 10: 23-28; discussion 79-83.

Stuffers S, Sem Wegner C, Stenmark H, Brech A. 2009. Multivesicular endosome biogenesis in the absence of ESCRTs. Traffic 10: 925-937.

Stupka N, Tarnopolsky MA, Yardley NJ, Phillips SM. 2001. Cellular adaptation to repeated eccentric exercise-induced muscle damage. J Appl Physiol (1985) 91: 16691678.

Sugiura A, McLelland GL, Fon EA, McBride HM. 2014. A new pathway for mitochondrial quality control: Mitochondrial-derived vesicles. EMBO J 33: 2142-2156.

Sutherland LN, Bomhof MR, Capozzi LC, Basaraba SA, Wright DC. 2009. Exercise and adrenaline increase PGC- $1 \alpha$ mRNA expression in rat adipose tissue. J Physiol 587: $1607-1617$

Tani S, Kuraku S, Sakamoto H, Inoue K, Kusakabe R. 2013. Developmental expression and evolution of muscle-specific microRNAs conserved in vertebrates. Evol Dev 15: 293-304.

Tarnopolsky M, Zimmer A, Paikin J, Safdar A, Aboud A, Pearce E, Roy B, Doherty T. 2007. Creatine monohydrate and conjugated linoleic acid improve strength and body composition following resistance exercise in older adults. PLOS ONE 2: e991.

ten Hacken NH. 2009. Physical inactivity and obesity: Relation to asthma and chronic obstructive pulmonary disease? Proc Am Thorac Soc 6: 663-667.

Thery C, Zitvogel L, Amigorena S. 2002. Exosomes: Composition, biogenesis and function. Nat Rev Immunol 2: 569-579.

Timmons JA. 2011. Modulation of microRNAs during exercise and disease in human skeletal muscle. Exerc Sport Sci Rev 39: 218; author reply 219.

Toth KG, McKay BR, De Lisio M, Little JP, Tarnopolsky MA, Parise G. 2011. IL-6 induced STAT3 signalling is associated with the proliferation of human muscle satellite cells following acute muscle damage. PLoS ONE 6: e17392.

Trajkovic K, Hsu C, Chiantia S, Rajendran L, Wenzel D, Wieland F, Schwille P, Brügger B, Simons M. 2008. Ceramide triggers budding of exosome vesicles into multivesicular endosomes. Science 319: 1244-1247.

Trounson A. 2013. A rapidly evolving revolution in stem cell biology and medicine. Reprod Biomed Online 27: $756-$ 764 .

Urbanelli L, Magini A, Buratta S, Brozzi A, Sagini K, Polchi A, Tancini B, Emiliani C. 2013. Signaling pathways in exosomes biogenesis, secretion and fate. Genes (Basel) 4: $152-170$.

Valadi H, Ekström K, Bossios A, Sjöstrand M, Lee JJ, Lötvall JO. 2007. Exosome-mediated transfer of mRNAs and 
microRNAs is a novel mechanism of genetic exchange between cells. Nat Cell Biol 9: 654-659.

van Niel G, Charrin S, Simoes S, Romao M, Rochin L, Saftig P, Marks MS, Rubinstein E, Raposo G. 2011. The tetraspanin CD63 regulates ESCRT-independent and -dependent endosomal sorting during melanogenesis. Dev Cell 21: $708-721$.

van Praag H, Kempermann G, Gage FH. 1999. Running increases cell proliferation and neurogenesis in the adult mouse dentate gyrus. Nat Neurosci 2: 266-270.

Wallenius V, Wallenius K, Ahrén B, Rudling M, Carlsten H, Dickson SL, Ohlsson C, Jansson JO. 2002. Interleukin-6deficient mice develop mature-onset obesity. Nat Med 8: 75-79.

Warburton DE, Charlesworth S, Ivey A, Nettlefold L, Bredin SS. 2010. A systematic review of the evidence for Canada's physical activity guidelines for adults. Int J Behav Nutr Phys Act 7: 39.

Weng Y, Sui Z, Shan Y, Hu Y, Chen Y, Zhang L, Zhang Y. 2016. Effective isolation of exosomes with polyethylene glycol from cell culture supernatant for in-depth proteome profiling. Analyst 141: 4640-4646.

Wiklander OP, Nordin JZ, O'Loughlin A, Gustafsson Y, Corso G, Mäger I, Vader P, Lee Y, Sork H, Seow Y, et al. 2015. Extracellular vesicle in vivo biodistribution is determined by cell source, route of administration and targeting. J Extracell Vesicles 4: 26316.
Wing RR, Reboussin D, Lewis CE; Look AHEAD Research Group. 2013. Intensive lifestyle intervention in type 2 diabetes. N Engl J Med 369: 2358-2359.

Wolfers J, Lozier A, Raposo G, Regnault A, Théry C, Masurier C, Flament C, Pouzieux S, Faure F, Tursz T, et al. 2001. Tumor-derived exosomes are a source of shared tumor rejection antigens for CTL cross-priming. Nat Med 7: 297-303.

Woodcock J, Franco OH, Orsini N, Roberts I. 2011. Nonvigorous physical activity and all-cause mortality: Systematic review and meta-analysis of cohort studies. Int J Epidemiol 40: 121-138.

Yáñez-Mó $M$, Siljander PR, Andreu Z, Zavec $A B$, Borràs FE, Buzas EI, Buzas K, Casal E, Cappello F, Carvalho J, et al. 2015. Biological properties of extracellular vesicles and their physiological functions. J Extracell Vesicles 4: 27066.

Zhang P, Hire D, Espeland MA, Knowler WC, Thomas S, Tsai AG, Glick HA; Look AHEAD Research Group. 2016. Impact of intensive lifestyle intervention on preferencebased quality of life in type 2 diabetes: Results from the Look AHEAD trial. Obesity (Silver Spring) 24: 856-864.

Zheng Selin J, Orsini N, Ejdervik Lindblad B, Wolk A. 2015. Long-term physical activity and risk of age-related cataract: A population-based prospective study of male and female cohorts. Ophthalmology 122: 274-280. 


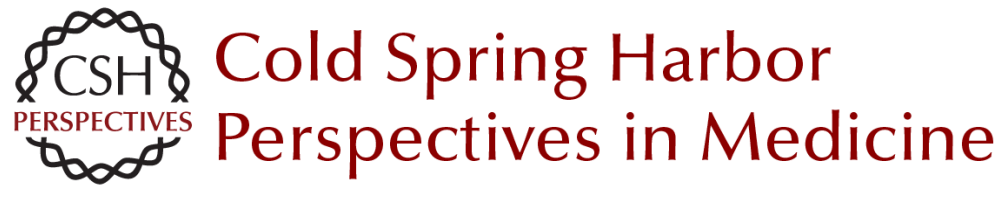

\title{
Exosomes as Mediators of the Systemic Adaptations to Endurance Exercise
}

\author{
Adeel Safdar and Mark A. Tarnopolsky
}

Cold Spring Harb Perspect Med 2018; doi: 10.1101/cshperspect.a029827 originally published online May 10,2017

\section{Subject Collection The Biology of Exercise}

\section{Exosomes as Mediators of the Systemic \\ Adaptations to Endurance Exercise Adeel Safdar and Mark A. Tarnopolsky}

Molecular Basis of Exercise-Induced Skeletal Muscle Mitochondrial Biogenesis: Historical Advances, Current Knowledge, and Future Challenges Christopher G.R. Perry and John A. Hawley

Exercise Metabolism: Fuels for the Fire Mark Hargreaves and Lawrence L. Spriet

Health Benefits of Exercise Gregory N. Ruegsegger and Frank W. Booth

Molecular Regulation of Exercise-Induced Muscle Fiber Hypertrophy

Marcas M. Bamman, Brandon M. Roberts and Gregory R. Adams

Physiological Redundancy and the Integrative Responses to Exercise Michael J. Joyner and Jerome A. Dempsey

On the Run for Hippocampal Plasticity C'iana Cooper, Hyo Youl Moon and Henriette van Praag

Molecular Basis for Exercise-Induced Fatigue: The Importance of Strictly Controlled Cellular $\mathrm{Ca}$ 2+ Handling Arthur J. Cheng, Nicolas Place and Håkan Westerblad
Effects of Exercise and Aging on Skeletal Muscle Giovanna Distefano and Bret $H$. Goodpaster

Muscle-Adipose Tissue Cross Talk Kristin I. Stanford and Laurie J. Goodyear

Performance Fatigability: Mechanisms and Task Specificity Sandra K. Hunter

Adaptations to Endurance and Strength Training David C. Hughes, Stian Ellefsen and Keith Baar

The Bioenergetics of Exercise P. Darrell Neufer

Effects of Exercise on Vascular Function, Structure, and Health in Humans Daniel J. Green and Kurt J. Smith

Control of Muscle Metabolism by the Mediator Complex Leonela Amoasii, Eric N. Olson and Rhonda Bassel-Duby

Theoretical and Biological Evaluation of the Link between Low Exercise Capacity and Disease Risk Lauren Gerard Koch and Steven L. Britton

For additional articles in this collection, see http://perspectivesinmedicine.cshlp.org/cgi/collection/ 